\title{
INSTRUMENTS AND METHODS USED IN RADIOMETRY.
}

\author{
By W. W. Coblentz.
}

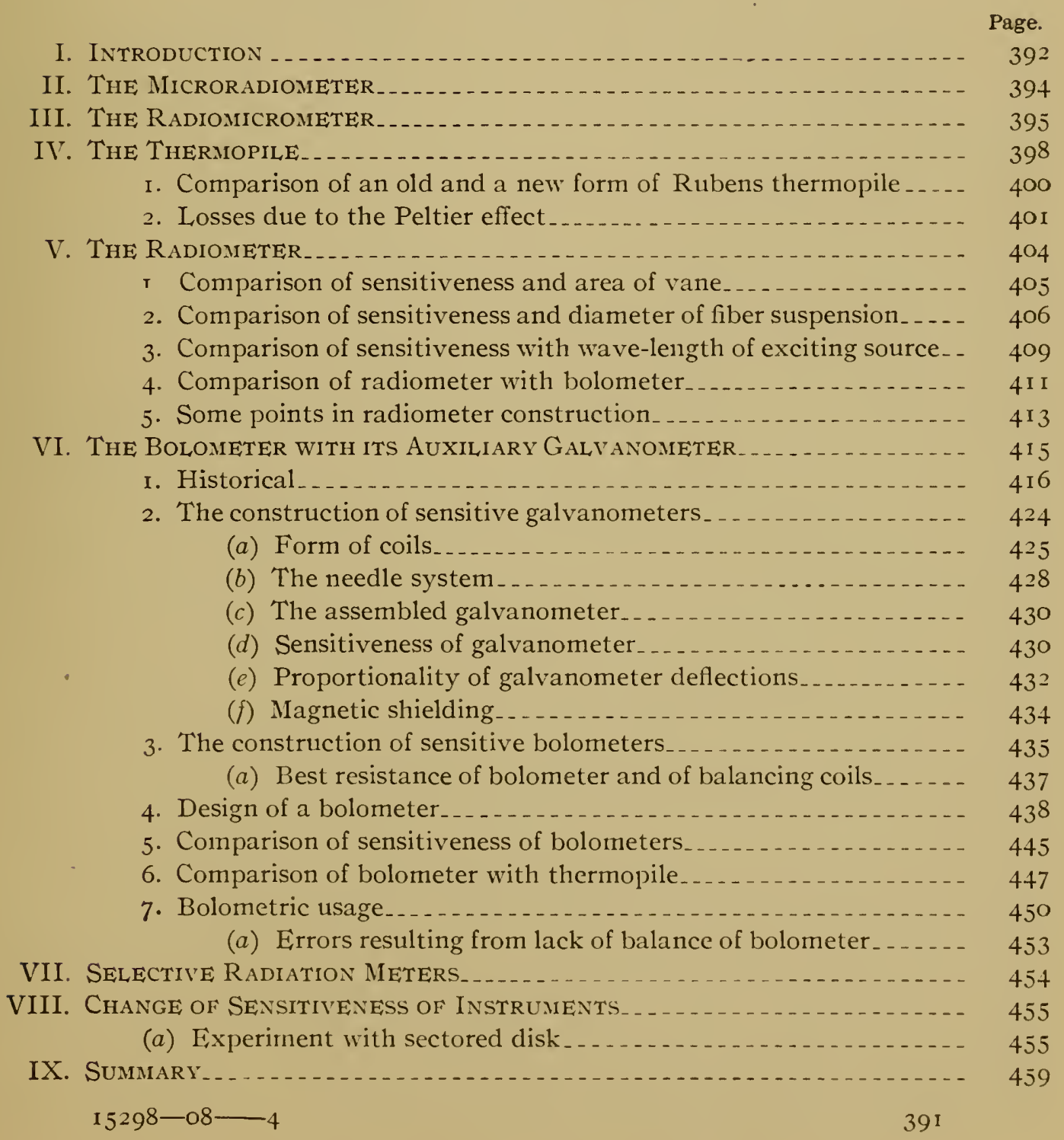




\section{INTRODUCTION.}

'There are few fields of experimental investigation so beset with difficulties as the quantitative measurement of radiant energy. This is clue chiefly to the fact that the radiation to be measured is generally from a surface, of which it is practically impossible to determine the temperature. 'The measurement of radiant energy, moreover, generally involves its transformation into some other form, and the receiver used for this purpose is subject to losses by heat conduction within, and by reflection, radiation, and convection losses from its surface.

As a result of inquiry into the development of the various instruments and methods used in measuring radiant energy, viz, the radiometer, the thermopile, the radiomicrometer and the bolometer with its auxiliary galvanometer, the writer has accumulated data, part of which are included here, with the hope that it may be useful to others interested in the subject. An attempt is also made to give the general principles involved in the construction and use of different radiation meters, as well as original experimental data of their relative efficiencies.

Much has been written on the theory and design of sensitive galvanometers and bolometers, and nothing radically new will be attempted in this paper. Not that improvements are impossible, but, as will be noticed presently, the working sensitiveness seems to have attained a fixed value for all of the various designs of galvanometer coils and magnet systems thus far described. It will also be noticed that the "working sensitiveness," at which it is possible to use the instrument with precision and convenience, and the highest attainable sensitiveness are two distinct factors in rating radiation meters. For example, it may be possible at certain hours of the day to read a bolometer-galvanometer deflection to o. I $\mathrm{mm}$. and thus detect a rise in temperature of, say, one tenmillionth degree, but for an instrument that is useful at all hours a fair estimate of the sensitiveness attained by various observers is about one-tenth to one-twentieth this value. It is practically impossible to buy instruments as sensitive as this. While galvanometers and thermopiles can be purchased, they often fall short of the specifications of the original, so that it is better to build the 
instrument in one's own laboratory. Here again one experiences the difficulty that the descriptions of such galvanometers and bolometers are scattered through so many journals that it becomes a burden to learn of the different improvements that have been made. For example, one may find a galvanometer with large coils, and a heavy magnet system, provided with an excellent magnetic shield. Again, one will find a galvanometer with small coils, and light suspension, built in such a manner that the latter is visible, which is a desirable feature, but the whole is enclosed in a large glass case which renders magnetic shielding very difficult. Furthermore, European investigators have used their bolometers and balancing coils in separate cases, and the bridge arms of equal resistance, while the latest developments in this country show that it is best to have the resistance of the bridge arms several times that of the bolometer strips, and the whole, including the balancing wire, enclosed in a single double walled case. These are some of the facts brought out by the writer's inquiry into the matter; and in designing the instruments to be described, and in the improvements suggested, an attempt was made to inciude as many as possible of the good points in the various instruments previously described, and to introduce simplifications wherever possible.

Various instruments for measuring radiant energy have been devised, the relative sensibilities of which can be rated without further investigation. That in many cases the sensitiveness has been overestimated will be noticed in the present paper. Four instruments, viz, the radiomicrometer, the thermopile, the bolometer, and the radiometer have been used extensively in radiation work, and in each case the investigators have found qualities which seemed to render each type of instrument superior to the others. But, so far as the writer has been able to learn, all four instruments have not been heretofore studied by any one person. Each instrument requires a special mode of handling, and has peculiarities which can be learned and controlled only after prolonged use. This is particularly true of the radiometer, and of the bolometer with its auxiliary galvanometer. Having already had considerable experience with radiometers, one of which was 
the most sensitive yet constructed, ${ }^{1}$ the writer has, in this examination, devoted most of his attention to the bolometer. The investigation originated for the most part from the question whether the radiometer was selective in its action in the region of short wave-lengths. In previous work it was found that the radiometer gave small deflections in the violet spectrum of the arc where Snow," using a bolometer, found large deflections.

In the course of the discussion it will be noticed, as was previously known in a general way, that each instrument has some quality which makes it useful for particular kinds of work. For measuring very narrow emission lines and determining dispersion curves the bolometer is no doubt the best instrument. For measurements requiring a larger receiving surface the linear thermopile is the more sensitive and the more precise. It has the further advantage that there is no permanent current. On the contrary, the bolometer has a current which heats the bolometer strips above the temperature of the surrounding air. This causes air currents which make the zero of the galvanometer unstable. This is not true of the thermopile. Less is known concerning the radiometer, which rivals the bolometer and the thermopile in sensitiveness. Furthermore, the radiometer is not subject to magnetic perturbations. Its window limits its usefulness to the region of the spectrum up to $20 \mu$. The fact that it is not portable is a minor objection.

An attempt is made in the present paper to discuss all the important details involved in radiometry, so that it will be possible to gain a knowledge of the subject without searching through the already extensive literature.

\section{THE MICRORADIOMETER.}

Since we are concerned with radiation meters of the greatest sensitiveness, the ingenious device of Weber, ${ }^{3}$ called the "microradiometer," deserves notice. The instrument is not unlike a combination of a differential air thermometer and a Wheatstone bridge. Two arms of the bridge consist of a thin glass tube con-

${ }^{1}$ See "Investigations of Infra-red Spectra," Part II. A still greater sensibility was attained in the present investigation.

${ }^{2}$ Snow, Physical Review, 1, p. 32; i 893.

3 Weber, Archiv. Sci. phys. et Nat. (3), 15, p. 347; 1887. 
taining a drop of mercury at the center, with a solution of zinc sulphate at the ends, into which dip platinum electrodes. The ends of the glass tube widen out into large bulbs containing air. The ends of the bulbs are covered with rock salt windows. If radiant energy is allowed to enter one of the bulbs, the air expands and pushes the liquids toward the opposite bulb. 'This will change the relative lengths of the column of mercury and of the solution between the platinum terminals, which means a change in resistance in the bridge arm and a consequent deflection of the galvanometer. The instrument was stated to be

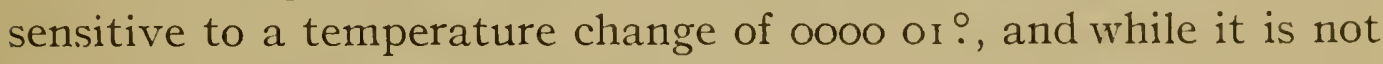
adapted to spectrum radiation measurements, it might be used in total radiation work where an elaborate installation is not convenient. By making the receiving bulb of opaque nonconducting material and covering the inside with lampblack, or platinum black, this would be as complete an absorber (black-body) as the thermopile or bolometer. Its efficiency would of course depend upon the gas enclosed.

\section{THE RADIOMICROMETER.}

The radiomicrometer is essentially a moving coil galvanometer having a single loop of wire with a thermo-junction at one end. This instrument was invented independently by d'Arsonva $1^{4}$ and by Boys. ${ }^{5}$ The former used a loop, one part of which was silver and the other was of palladium. The latter used a junction of bismuth and antimony, which was soldered to a loop of copper wire.

The sensibility of the Boys instrument was given as $\overline{10} \frac{1}{0} \overline{0} \frac{0}{0}$ to $\bar{y} \frac{1}{0} \overline{0} \overline{0} \overline{0}$ of $\mathrm{I}^{\circ}$. From subsequent work with other radiation meters in which this high degree of sensitiveness has never been attained, it would appear that the sensibility of the radiomicrometer was overestimated. It certainly has never attained the sensibility of the radiometer, one example of which, used by Nichols (loc. cit. Table III), was I 2 times as sensitive as the radiomicrometer of Boys. The latter gave a deflection of a

${ }^{4}$ d'Arsonval, Soc. Franc. de Phys., pp. 30 and $77 ; 1886$.

${ }_{5}^{5}$ Boys, Proc. Roy. Soc., 42, p. I89, I887; 44, p. 96, I888; 47, p. 480, I89o; Phil. Trans., 150A. p. I 59, I 889 
little less than $\mathrm{I} \mathrm{cm}$ per $\mathrm{mm}^{2}$ of exposed vane for a candle and scale each at a distance of I meter. Paschen $^{6}$ attempted to improve the radiomicrometer, but out of about fifty junctions only three were useful, and these were only three times as sensitive as that of Boys, while the period was about forty seconds. The long period is not always detrimental, however, for the radiomicrometer is not subject to magnetic disturbances and is a very useful instrument for work not requiring the highest attainable sensitiveness. The writer ${ }^{7}$ has indicated further improvements in the instrument, and places it in a vacuum, which increases the sensibility by at least 70 per cent. The instrument was about six times as sensitive as that of Boys for a full period of $25 \mathrm{sec}-$ onds. Para- and dia-magnetism limited the sensitiveness to this value. The work with this instrument brought out the fact that one may use too strong field magnets and that further improvement may be made by using weak magnets, or by using narrow strong magnets situated as far as possible above the thermojunction, so as to avoid the effect of para- or dia-magnetism. The combination of the radiomicrometer and the radiometer is feasible, although the writer found its usefulness as limited as that of the radiomicrometer. When wires can be obtained more free from magnetic material it will be possible to construct a more sensitive instrument. It is doubtful, however, whether it will ever surpass the bolometer used with a galvanometer of the highest sensibility. With the radiomicrometer, Lewis ${ }^{8}$ was able to investigate infra-red emission spectra of the alkali metals, which are weak in energy. Wilson ${ }^{9}$ and Julius ${ }^{10}$ have used the radiomicrometer for total and spectrum radiation work, and found the instrument highly satisfactory. The long period (which also obtains in other sensitive radiation meters) and lack of portability, mentioned by some writers, is certainly not to be weighed against its indifference to magnetic perturbations and constancy of the zero reading. Even a slow period is less objectionable than a quick-period instrument with which just as

\footnotetext{
${ }^{6}$ Paschen, Ann. der. Phys. (3), 45, p. 272; 1893.

- This Bulletin, 2, p. 479; I906.

${ }^{8}$ Lewis, Astrophys. J., 2, p. I; 1895.

${ }^{9}$ Wilson, Proc. Roy. Soc., 55, I894; 5S, 1895; 60, p. 337; 1896

${ }^{10}$ Julius, Handlingen, 5, de Nederlandisch Natuur en Geneeskundig Congres; 1895.
} 
much time is lost by repeating observations, which may be affected by the lack of constancy of the zero. The instrument is selfcontained and where the greatest sensitiveness is not required, it deserves a wider application. In Table I are given the various radiomicrometers thus far described and their sensitiveness, expressed in centimeter deflections per $\mathrm{mm}^{2}$ of exposed vane, for a candle and scale each at a distance of I meter.

It will be shown below that the highest efficiency is obtained when the resistance of the thermocouple is equal to the combined resistance of the connecting wires and of the auxiliary galvanometer. Since the resistance of a single couple is much less than that of the galvanometer, it is most advantageous to use several pairs of junctions. On the other hand, in the radiomicrometer the connecting loop of wire has a negligible resistance, and hence there is no advantage in using more than a single pair of junctions; for as we increase the electromotive force by adding junctions the resistance is increased in like proportion, so that the current remains practically constant. For like reasons there is no advantage in using more than one turn of wire in the connecting loop.

\section{TABLE I.}

Sensitiveness of Radiomicrometers and Rubens Thermopile.

\begin{tabular}{|c|c|c|c|}
\hline Observer & Full period & Area of vane & $\begin{array}{l}\text { Deflections in } \mathrm{cm} / \mathrm{mm}^{2} \\
\text { candle and scale at } \mathrm{Im}\end{array}$ \\
\hline 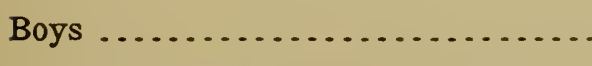 & $10 \mathrm{sec}$. & $4 \mathrm{~mm}^{2}$ & $0.9 \mathrm{~cm}$ \\
\hline Phil. Trans., 180 A, p. 159, 1889. & & & \\
\hline Paschen...$\ldots \ldots \ldots \ldots \ldots \ldots$ & 40 & & 3 \\
\hline Wied. Ann., 48, p. 275, 1893. & & & \\
\hline $\begin{array}{l}\text { Lewis } \ldots \ldots \ldots \ldots \ldots \\
\quad \text { Astrophys. Jour., } 2, \text { p. } 1,1895 .\end{array}$ & 20 & 1.4 & $1.3(?)$ \\
\hline Coblentz $\ldots \ldots \ldots$ & 40 & 3 & 3.6 \\
\hline $\begin{array}{l}\text { This Bulletin } \\
\text { 2, p. } 479,1906 .\end{array}$ & 25 & 3 & 6 (in vacuo) \\
\hline
\end{tabular}

Thermopile.

\begin{tabular}{|c|c|c|c|}
\hline $\begin{array}{l}\text { Rubens .... } \\
\quad \text { Wied. Ann., 45, p. 244, } 1898 .\end{array}$ & 14 & $16(?)$ & $\begin{array}{l}16(250 \mathrm{~cm} \text { total deflection }) \\
1 \mathrm{~mm}=1: 1 \times 10^{-6} \mathrm{C} .\end{array}$ \\
\hline
\end{tabular}




\section{THE THERMOPILE.}

The thermopile has been in use from the very beginning of radiant energy measurements, and in the hands of 'Tyndall and other pioneers in this domain has rendered excellent service in spite of its great heat capacity. For spectro-radiometric work, however, only the linear thermopile of Rubens ${ }^{11}$ is well adapted. 'This thermopile consists of 20 junctions of iron and constantan wires about $0.1 \mathrm{~mm}$ to $0.15 \mathrm{~mm}$ diameter (resistance $3.5 \mathrm{ohms}$ ), and when used with a galvanometer, having a figure of merit of $i=\mathrm{I} .4 \times 1 \mathrm{IO}^{-10}$ amperes (resistance $=3$ ohms, period $=\mathrm{I} 4$ seconds) a deflection of one scale division indicated a temperature ${ }^{12}$ change of $\mathrm{I}^{\circ}$. I $\times \mathrm{IO}^{-6}$. A candle at $5 \mathrm{~m}$ gave a deflection of about $10 \mathrm{~cm}$ or $250 \mathrm{~cm}$ at $\mathrm{I} \mathrm{m}$. The area of exposed face of pile is about $0.8 \times 20 \mathrm{~mm}$. The deflections were as rapid as for a bolometer, and its stationary temperature was reached in less time than the single swing of the galvanometer needle. In other words, its heat capacity was so small that it gave an accurate register of the energy falling upon it. In another experiment, using a galvanometer sensitiveness of $i=5 \times \mathrm{IO}^{-10}$ amperes, and the scale at $\mathrm{I}$ meter, $\mathrm{I} \mathrm{mm}$ deflection $=2.2 \times \mathrm{IO}^{-6}$. The sensitiveness is the same as that of the best bolometers yet constructed, while its simplicity commends itself even in spectrum radiation work.

The general experience in this country, however, has been that the commercial instrument does not fulfill all the excellent qualities claimed for the one originally described. The wires are heavier than in the original specifications, which makes the instrument sluggish.

The problem in thermopile construction is to secure a low resistance (equal to that of the galvanometer), a low heat capacity

${ }^{11}$ Rubens, Zs. für Instrumentenkunde, 18, p $65 ; 1898$.

${ }^{12}$ If $p=$ the thermoelectric power in microvolts per degree $(=53$ microvolts for iron and constantan), $n=$ number of junctions exposed and $r=$ the internal resistance, of the thermopile; and if we combine the pile with a galvanometer, which, with an internal resistance of $w \mathrm{ohms}$, gives a deflection of $m$ millimeters per microampere, then a deflection of $\mathrm{I} \mathrm{mm}$ indicates a change in temperature of the junctions of $\Delta t$ degrees where

$$
\Delta t=\frac{r+w}{n p m}
$$


and heat conductivity, and a high thermoelectric power. The latter requirement is fulfilled by using junctions of iron and constantan. The heat capacity can be reduced by using finer wire, say 0.06 to $0.08 \mathrm{~mm}$ diameter, and by making the unexposed junctions smaller than the ones to be exposed. The junctions are soldered with quite large beads of silver, which are then flattened to present a large surface. The unexposed junctions do not need this, and the small bead formed by the fusion of the two wires (with a bit of silver solder if necessary) can be hammered thin, in order to have it radiate rapidly. By using finer wires (to reduce heat conduction) the resistance will be increased if the dimensions of the Rubens pile be retained. In the commercial instrument,
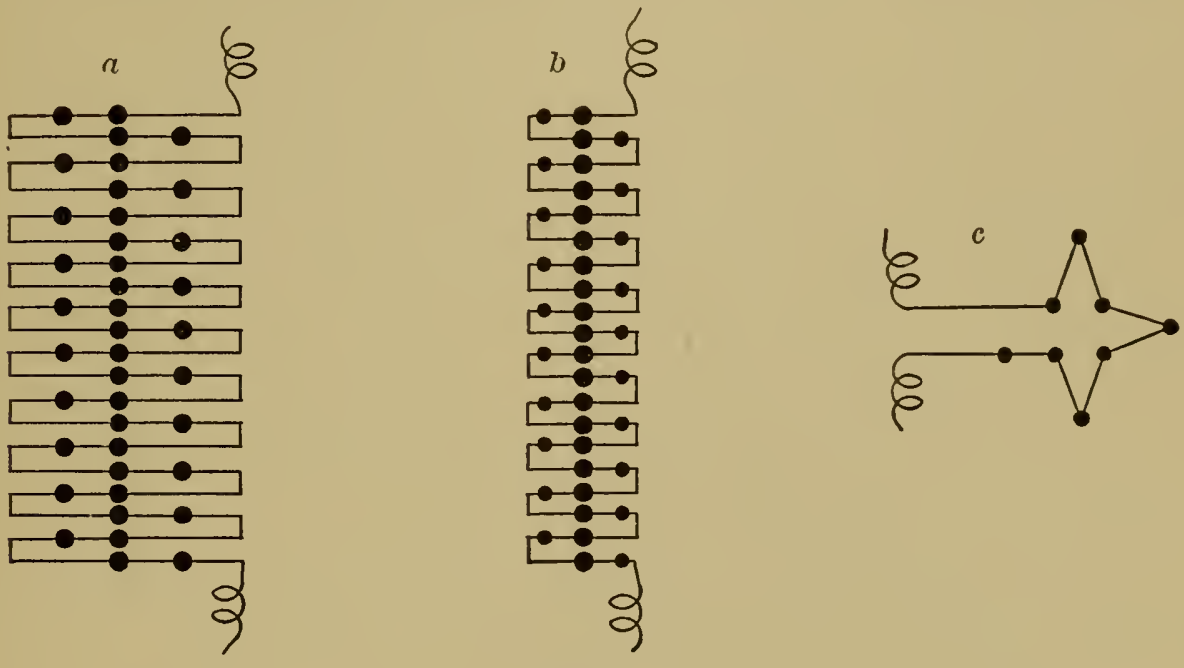

Fig. 1.

at least one-third of the wire is between the unexposed junctions and the binding posts. The greater part of this wire may be eliminated by making the supporting frame narrower, while still retaining the original distance between the exposed and the unexposed junctions. The elimination of this superfluous wire will reduce the resistance by about one-third. In Fig. I is shown the original design, $a$, and the suggested improved design $b$. In Fig. I $c$, is shown, on an enlarged scale, a thermopile for "point" sources. By using iron and constantan wires 0.06 to $0.08 \mathrm{~mm}$ diameter it is possible to place quite a number of junctions within a small area. The combination could be used to advantage in a Féry pyrometer, and for measuring radiation from sun spots, 
etc., in which the bolometer, on account of the smallness of the exposerl surface, is lacking in sensitiveness. By properly arranging the groups, of four or more junctions each, the combination will take the form of a hollow enclosure, which would tend to make it a more complete absorber of radiant energy.

1. Comparison of Old and New Form of Thermopile.-In order to test these conclusions in regard to the use of finer wire, a new iron-constantan pile of 20 junctions, made of wire $0.08 \mathrm{~mm}$ diameter, was ordered from the makers of the original instrument. Although the specifications were not completely fulfilled (the frame was nearly the same size as the original, which increased the resistance to 9 ohms), the sensitiveness was 1.4 times that of the old type, which has a resistance of 4.8 ohms (wire about o.I 5 $\mathrm{mm})$. By means of suitable switches the two thermopiles were connected to the same galvanometer, having a full period of i 2 seconds ( $i=2 \times 10^{-10}$ amperes) and exposed to the radiation from a Nernst heater. For all deflections, as large as $35 \mathrm{~cm}$, the new thermopile showed no drift greater than $\pm_{2} \mathrm{~mm}$, which may be attributed to the galvanometer. On the other hand, the zero of the old thermopile would drift $0.5 \mathrm{~cm}$ in a $10 \mathrm{~cm}$ deflection to $2.2 \mathrm{~cm}$ in a $27 \mathrm{~cm}$ deflection, and it would require $\mathrm{I} 5$ to 20 seconds for the deflection to become zero.

The two instruments were then tested in a vacuum. The sensitiveness of the old instrument was increased only i 5 per cent, while no change in sensitiveness could be detected in the new one, although two distinct tests were made on different days, the pressure having been reduced to o.or $\mathrm{mm}$. The thermopiles are mounted on ivory frames and covered with a sheet of copper, one side having a slit the other a funnel-shaped opening ( $\left.X \mathrm{I}_{5} \mathrm{~mm}\right)$. The slit was covered and the radiation passed through the funnel. The whole was suspended from a rubber cork in a wide-mouthed bottle, which was exhausted with a mercury or a Geryk pump. The source of energy was an incandescent lamp. With $200 \mathrm{ohms}$ in series with the galvanometer the deflections were about $10 \mathrm{~cm}$. The fact that the sensitiveness of these thermopiles did not increase appreciably in a vacuum is rather remarkable. Brandes ${ }^{13}$

${ }^{13}$ Brandes, Physikal. Zs., 6, p. 503; I 905. 
found that a single junction of $0.02 \mathrm{~mm}$ wire became is times more sensitive in a vacuum. Lebedew ${ }^{14}$ found that a $0.025 \mathrm{~mm}$ iron and constantan junction, when black, was 7 times, and when bright was 25 times, more sensitive at a pressure of $0.01 \mathrm{~mm}$ than at atmospheric pressure.

Since writing the above an investigation of Moll ${ }^{15}$ has appeared, in which he used a modified form of Rubens thermopile. The iron-constantan wires were $0.06 \mathrm{~mm}$ diameter, the junctions were $0.2 \mathrm{~mm}$ diameter, while the resistance was $\mathrm{r} 2 \mathrm{ohms}$. The galvanometer sensibility was $i=\mathrm{I} \times \mathrm{IO}^{-8}$ amperes (not very sensitive), and had a full period of $\mathrm{I} 2$ seconds. The radiation curves were

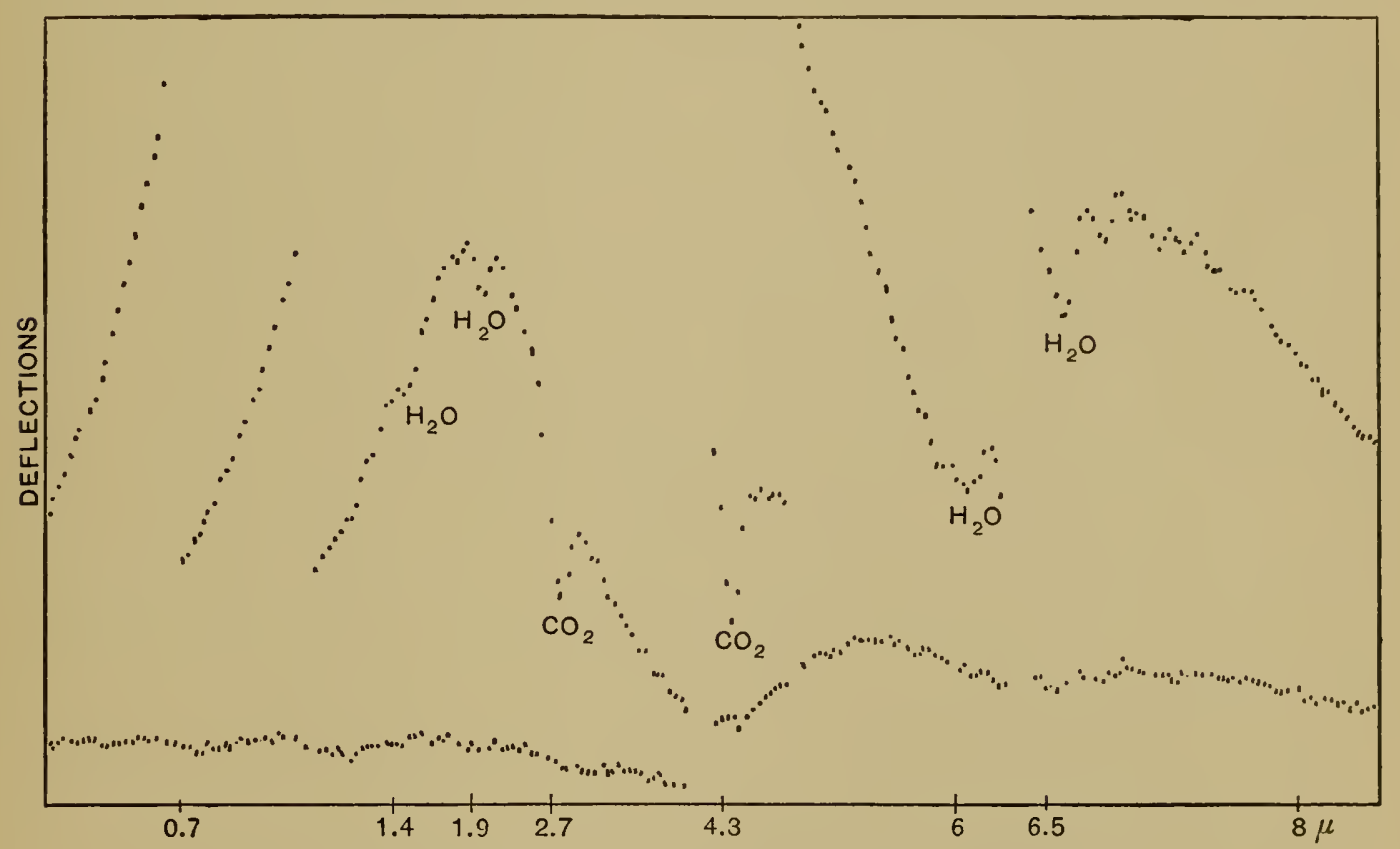

Fig. 2.-Energy curve of Nernst Glower. (Moll.)

recorded automatically by a device that also registered the zero of the instrument after each deflection. The curves must therefore be free from any personal bias, and one is reproduced in Fig. 2 to show that the thermopile of fine (.06 to $.08 \mathrm{~mm}$ ) wire deserves more consideration than it has heretofore received.

2. The Peltier Effect.- The result of the Peltier effect is to lower the temperature of the exposed junction. Consequently, the thermopile does not give an accurate record of the energy

${ }^{14}$ L,ebedew, Ann. der Phys. (4) 9, p. 209; I902.

${ }^{15}$ IV. J H. Moll, Dissertation, Utrecht. February, I907. 
received. The actual error introduced has never been determined. Since there is a possibility of using the thermopile for quantitative work in place of the bolometer, it is desirable to learn the degree of accuracy of this instrument.

The rate of generation of heat by the Peltier effect is proportional to the current, while the generation of heat on account of resistance is proportional to the square of the current. Jahn ${ }^{16}$ las shown that the heat generated by the Peltier effect, determined experimentally, agrees, within experimental error, with the value computed from the observed thermoelectric power. 'The value for iron-constantan has never been determined experimentally ${ }^{16 a}$ but from the work of Jahn it is permissible to compute the heat generated in the thermopile by using the known thermoelectric power, which is about $50 \times 10^{-6}$ volts.

Using a galvanometer of $5 \mathrm{ohms}$ resistance and having a figure of merit of $i=3 \times \mathrm{IO}^{-10}$ amperes per $\mathrm{mm}$ for a scale at $\mathrm{I} \mathrm{m}$, and an iron-constantan thermopile of 20 junctions, wire $0.08 \mathrm{~mm}$ and 5 ohms resistance (see footnote 12 );

$$
\text { I } \mathrm{mm}=2 \times 1 \mathrm{O}^{-6} \text { degree. }
$$

The Peltier effect in calories is computed from the formula:

$$
P=\frac{T i t}{J} \quad \frac{d E}{d t}
$$

where $T=274^{\circ}, i=3 \times 10^{-11}$ c.g.s. units, $t=5$ seconds, $J=$ $4.2 \times 1 \mathrm{O}^{-7}$ and $d E / d t=50 \times 1 \mathrm{O}^{-2}$ c.g.s. units,

$$
\therefore P= \pm 5 \times \mathrm{IO}^{-18} \mathrm{gr} \text {.-cal. (in } 5 \text { seconds). }
$$

The total weight of the junctions is about o.or gr. and the specific heat is about o.I gr.-cal.

Hence the temperature change of the exposed junctions is:

$$
\Delta t=\frac{5 \times 10^{-12}}{\mathrm{O} . \mathrm{I} \times \mathrm{O} . \mathrm{OI}}=5 \times 1 \mathrm{O}^{-9} \text { degree (for } \mathrm{I} \mathrm{mm} \text { deflection) }
$$

and since the temperature of the unexposed junctions is changed an equal amount in the opposite direction the total change $\Delta t=\mathrm{I} \times 1 \mathrm{IO}^{-8}$ degree. But a deflection of $\mathrm{I} \mathrm{mm}=2 \times 1 \mathrm{O}^{-6}$

${ }^{16} \mathrm{Jahn}$, Wied. Ann., 34, p. $755 ; 1898$.

${ }^{16 a}$ Since writing this it has been found that Lecher, Ber. Akad. Wiss. Wien., 115, p 1505, 1906; Sci. Abstracts, 1083, 1907, has recently determined this constant to be 12.24 gr.-cal. per amp.-hr., while the value previously computed was $10.5 \mathrm{gr}$-cal. per amp.-hr 
degree, hence the error is I part in 200 under the best theoretical conditions. In practice the temperature sensitiveness will not be so great; it will be shown presently to be of the order $5 \times 10^{-6}$ degree, whence the Peltier effect would canse an error of I part in 500 , or $1 \mathrm{~mm}$ in $50 \mathrm{~cm}$, which is as close as one can read such large deflections. Since the Joule heat depends upon the square of the current, it is negligible. Further consideration of the thermopile as an instrument for quantitative measurements will be found below in connection with the bolometer.

It will be noticed presently, that prior to his construction of the iron-constantan thermopile, Rubens used several very sensitive bolometers, all of which were displaced by the thermopile. For exploring spectra with very narrow lines, the linear bolometer is probably better adapted than the pile which, however, may be covered with a diaphragm, having a narrow slit. For extreme sensitiveness it equals the bolometer, and it is a noteworthy fact that all the investigations in the extreme infrared and ultra-violet parts of the spectrum, where the energy is weak, have been accomplished by means of the thermopile. Unless one can build up an elaborate bolometric apparatus in a room not exposed to direct sunlight, the thermopile will give the more reliable readings, as far as the constancy of the zero is concerned. Whether or not the thermopile will give a true measure of the energy falling upon it will depend upon the manner in which it is employed. It requires no particular skill to manipulate, and is easier to protect against temperature changes than is a bolometer with its storage battery. The older form of thermopile used by Melloni, Tyndall, and others were subject to drift similar to that observed with the bolometer. This was not due to unequal increments of resistance, as in the bolometer, but to thermoelectric effects at the binding screws, to the connecting wires moving in the earth's magnetic field, and principally to the large heat capacity of the junctions. Most of these disturbances, however, are small and easily avoided in the Rubens type of thermopile. Since the bolometer strips and the balancing coils are of dissimilar material, it is also subject to thermoelectric disturbances. 


\section{THE RADIOMETER.}

The manner in which an interesting scientific toy can be made to serve a useful purpose is well exemplified in the radiometer of Crookes, ${ }^{17}$ discovered about 1875 . By fastening bits of pith (the one black, the other white) at the ends of a long straw, which was suspended by means of a silk fiber in a long glass tube, he was able to make measurements of radiant energy, even at that early date. Pringsheim ${ }^{18}$ simplified the instrument somewhat, suspended the vanes bifilarly with silk thread, and used it to investigate the infra-red spectrum of the sun, produced by means of a glass prism, to about I. $5 \mu$. From this the first really useful radiometer was developed by Nichols. ${ }^{19}$

It consists of two similar thin vanes of blackened mica or platinum attached to a horizontal arm, and suspended in a vacuum by means of a fine quartz fiber. The vanes are about $3 \mathrm{~mm}$ from the window. The radiation to be measured falls upon one of the vanes, which becomes slightly warmed. This causes the residual gas molecules to rebound with increased velocity from the blackened surface, and the reaction pushes the vane from the window. There is a small mirror attached to the glass staff which supports the vanes, and the deflection is observed by means of a telescope and scale. At certain gas pressures the exposed vane is attracted toward the window instead of being repelled from it. The behavior of the radiometer has been worked out theoretically by Maxwell ${ }^{20}$ in his paper on "Stresses in Rarefied Gases Arising from Inequalities of Temperature." Among other things, he showed that for two parallel disks very near each other the central points will produce but little effect, because between the disks the temperature varies uniformly, and only near the edges will there be any stress arising from an inequality of temperature in the gas. It has been shown by others, especially by Crookes and by Nichols, that the sensitiveness of the radiometer is a function of the pressure of the residual gas, of the kind of gas surrounding the vanes, and

\footnotetext{
${ }^{17}$ Crookes, Phil. Trans. (II), 166, p. $325 ; 1876$.

${ }_{18}$ Pringsheim, Ann. der Phys. (3), 18, p. 32; 1883.

${ }^{19}$ Nichols, Phys. Rev., 4, p. 297; 1897 . Ber. der Berliner Akad., p. I 183; 1896.

${ }^{20}$ Maxwell, Collected Papers, 2, p. 681. Phil. Trans., Part I, r879.
} 
of the distance of the exposed vanes from the window. The latter, on account of its absorption, limits the region of the spectrum that can be investigated. If the vanes are not too close to the window, the deflections will be proportional to the energy falling upon one of them.

1. Comparison of Sensitiveness and Area of Vane.-For vanes of small dimensions, such as must be used in practical work, the writer has found that the deflections are proportional to the area of the exposed surface of the vane. This is perhaps to be expected, although there seemed to be some doubt. The curve, Fig. 3, of

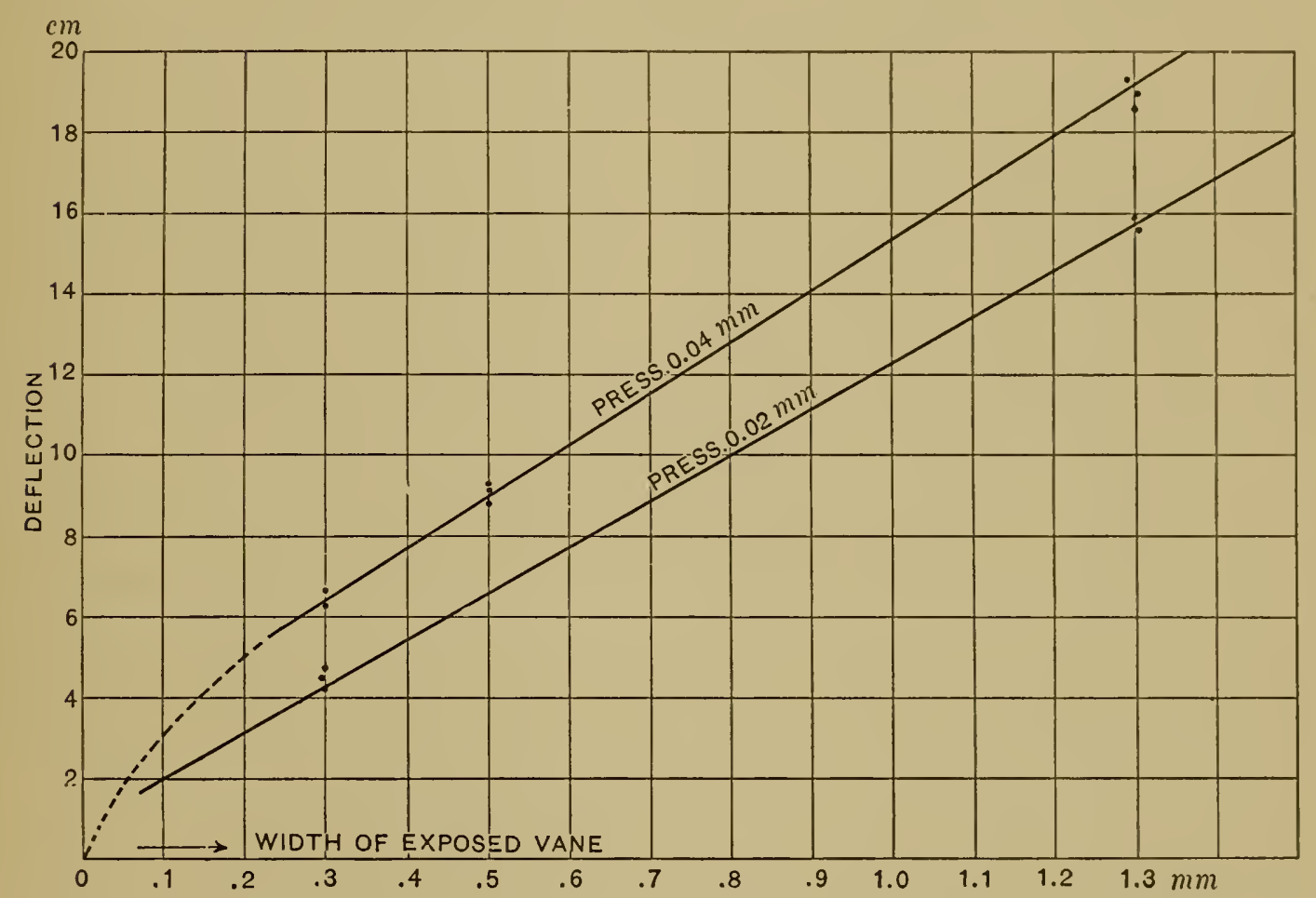

Fig. 3.-Variation of Radiometer deflections with area exposed.

deflections and exposed area of vanes (area $10.5 \times 1.3 \mathrm{~mm}$ for constant pressure of $0.02 \mathrm{~mm}$ ) does not pass through the origin. One explanation may be that for infinitely narrow vanes the graph is not a straight line, but curves as it approaches the origin. Because of the impracticability of suspending vanes of different widths successively from the same fiber suspension, at the same distance from the window, and using the same gas pressure for all vanes, it was necessary to use one wide vane, with a slit before it, and vary the opening of the slit. The source of energy (Nernst 
heater) was at a distance of 3 meters, and hence the width of the projection of the slit upon the vane was practically the width of the slit, except for a very narrow slit when diffraction may decrease somewhat the energy incident on the vane. 'This, however, would displace the graph still farther from the origin. 'The forces acting in a radiometer are so complex and so little understood that no further examination was made to ascertain the limits within which the above proportionality holds. The test of proportionality was made to reduce the deflections to unit area between the above limits of exposed vane. It is of interest to note in this connection that in a bolometer the sensitiveness varies as the square root of the area of the bolometer strip.

In his earlier communications the writer held to the belief that the weight of the vanes and their size were the most important factors in determining the sensitiveness and period of a radiometer. However, so many factors enter into the problem that it is difficult to decide this point, and the following test may be of interest, showing that the diameter of the quartz fiber suspension is an important factor in determining the sensitiveness.

2. Comparison of Sensitiveness and Diameter of Fiber Suspension.-Using the same vanes $(0.5 \times 9 \mathrm{~mm}$ area) the sensitiveness and period were found for a heavy and a light quartz fiber suspension. The main difficulty was to insure that the vanes were at the same distance from the window, and that the pressure was the same in the two cases. Hence these quantities are only approximate. In Table II it will be noticed that in changing from a heavy to a light fiber the sensitiveness is increased 4.5 times, while the period was increased almost three fold. It further shows that for the same (light) fiber the sensitiveness was doubled ( 36 to $7 \mathrm{I} \mathrm{cm}$ per $\mathrm{mm}$ ) by changing the pressure and the distance from the window, which was of fluorite and hence opaque beyond io $\mu$. The sensitiveness of $7 \mathrm{I} \mathrm{cm}$ per $\mathrm{mm}^{2}$ of exposed area is the highest on record. This, however, was not the maximum sensitiveness, since the pressure was $0.02 \mathrm{~mm}$, while radiometers have their maximum sensitiveness at a pressure of about 0.05 to $0.1 \mathrm{~mm}$. At this pressure, however, heat conduction would cause annoyance. The vanes of this suspension were of platinum foil o.o I mm thick, covered on one side electrolytically with platinum black and then 
smoked over a candle. It is best to cool the gases from the flame by placing a wire gauze, or sheet of metal full of holes, between the flame and the vanes when smoking them. These vanes were suspended by means of one of the finest workable quartz fibers, and when within $3 \mathrm{~mm}$ of the window either one of the vanes would always approach and adhere to it, even at atmospheric pressure. From tests with fluorite windows, which from internal strains might be piezoelectric, and with rock salt windows when bare and also when covered with tinfoil, it was found that this effect is not due to electrification. Starting with the vanes parallel and at a distance of about $5 \mathrm{~mm}$ from the window it was found that, as this distance was decreased, one of the vanes (generally the one to be exposed to radiation) would approach the window, and for a distance of about $3 \mathrm{~mm}$ would turn until the plane of the vanes was at right angles to the window. The observations extended over several months, and all evidence indicates that this effect is due to gravitational attraction. As a result of this the deflection of such a vane would not be proportional to the energy received. This radiometer had no torsion head to control the zero. However, for general work with very sensitive radiometers a torsion head would be necessary since the best pumps may leak, which will cause a slow drift. It will be shown presently that this is about 5 times the sensitiveness of Snow's bolometer, for which I $\mathrm{mm}$ deflection (scale at $3 \mathrm{~m}$ ) indicated a temperature difference of $7.6 \times 10^{-6}$. In other words, this radiometer would detect $\bar{\tau} \overline{0} \overline{0} 0 \overline{0} \overline{0}$ degree rise in temperature. But the period of the radiometer was 6 times that of the bolometergalvanometer, which is its weakest point in radiation work requiring a short period.

A comparison can also be made (Table II) between light vanes $(0.5 \times 9 \mathrm{~mm})$ and heavy ones $(1.3 \times 10.5 \mathrm{~mm})$ at the same pressure but having different quartz fiber suspensions. The results show that while the light vanes are more sensitive than the heavy ones (see Table III), there seems to be no limit to the sensitiveness attainable in either case, without considering the period. The idea of not considering period of vibration with sensitiveness seems reasonable, for by sensitiveness is meant the minutest I529S-OS- 5 
quantity of radiation one can detect, assuming one is willing to wait long enough for the deflection to reach a maximum. In Table III are compiled the most notable radiometers used in radiation work. The candle as a standard of comparison is not ideal, but since the sensitiveness of the various instruments varies

TABLE II.

Sensitiveness of Radiometers.

\begin{tabular}{|c|c|c|c|}
\hline Pressure & Full Period & $\begin{array}{c}\text { Deflection } \\
\text { per } \mathrm{mm}^{2}\end{array}$ & Remarks \\
\hline $\begin{array}{l}0.02 \mathrm{~mm} \\
.02 \text { ، }\end{array}$ & 45 secs. & $\begin{array}{l}7.9 \mathrm{~cm} \\
11.5 \text { " }\end{array}$ & $\begin{array}{l}\text { Vanes (area } 0.5 \times 9, \mathrm{~mm} \text { weight } 5 \mathrm{mg} \text { ) } 3 \mathrm{~mm} \\
\text { from window. } \\
\text { Vanes closer to window. }\end{array}$ \\
\hline
\end{tabular}

Same vanes $(0.5 \times 9 \mathrm{~mm})$, finer quartz fiber.

\begin{tabular}{|c|c|c|c|}
\hline Pressure & Full Period & $\begin{array}{l}\text { Deflection } \\
\text { per } \mathrm{mm}^{2}\end{array}$ & Remarks \\
\hline $0.02 \mathrm{~mm}$ & 2 min. & $36 \mathrm{~cm}$ & Vanes $3 \mathrm{~mm}$ from window candle at $3 \mathrm{~m}$. \\
\hline $0.03 ،$ & 2.5 & 71 & $\begin{array}{l}\text { Vanes nearer window. This is the greatest } \\
\text { recorded sensitiveness. A deflection of } 1 \\
\mathrm{~mm} \text { on scale at } 1 \mathrm{~m}=2.5 \times 10^{-6} \text {. }\end{array}$ \\
\hline 0.04 “ & $\ldots$ & 63.5 & \\
\hline
\end{tabular}

Heavy vanes, area $1.3 \times 10.5 \mathrm{~mm}$, weight $10+\mathrm{mg}$.

\begin{tabular}{|c|c|c|c|}
\hline $0.02 \mathrm{~mm}$ & secs. & $5.5 \mathrm{~cm}$ & Distance of vanes from window unknown. \\
\hline .02 ، & 60 to 64 & 13.7 " & Vanes nearer window, hence longer period. \\
\hline .026 ، & 36 to $40 \quad 6$ & 8.56 & Vanes farther from window than in preceding. \\
\hline .035 6 & 25 & 3.36 & $\begin{array}{l}\text { Vanes still farther from window, which } \\
\text { shortens period and decreases sensitiveness. } \\
\text { For a pressure of about } 0.05 \mathrm{~mm} \text { the sensi- } \\
\text { tiveness would be much greater. }\end{array}$ \\
\hline
\end{tabular}

by a factor from 2 to 20 , it is sufficiently accurate for the present comparison. In this table it will be noticed that for the same period the various radiometers vary in sensitiveness by as much as 50 per cent. Porter's radiometer was the most sensitive of the instruments having a period of 90 seconds. But he gained little on the whole, for the vanes were so light that he could work only 
during quiet hours at night. On the other hand, the writer, after trying light vanes, adopted heavy ones, ${ }^{21}$ and was thus enabled to continue his observations at all hours without annoyance even from a large air compressor which was situated in an adjoining basement room.

TABLE III.

Sensitiveness of Various Radiometers.

\begin{tabular}{|c|c|c|c|c|}
\hline \multirow{4}{*}{$\begin{array}{l}\text { E. F. Nichols......................... } \\
\text { Phys. Rev., 4, p. 297, } 1897 . \\
\text { Astrophys. Jour., 13, p. 101, } 1901 .\end{array}$} & \multirow{2}{*}{$\begin{array}{r}\text { Full period } \\
12 \text { secs. }\end{array}$} & \multirow{3}{*}{$\frac{\begin{array}{c}\text { Area of vanes } \\
\mathrm{mm}^{2}\end{array}}{2 \times 15}$} & \multicolumn{2}{|c|}{$\begin{array}{l}\text { Deflections permm } \\
\text { area of exposed } \\
\text { vane, candle and } \\
\text { scale each at } 1 \mathrm{~m}\end{array}$} \\
\hline & & & 5 & $\mathrm{~cm}(?)$ \\
\hline & & & & \\
\hline & 11 “ & 3.1 & 12.5 & “ \\
\hline Stewart $\ldots \ldots \ldots \ldots \ldots \ldots \ldots \ldots$ & $80 \lll$ & 30 & 4.9 & “ \\
\hline Phys. Rev., 13, p. 257, 1901. & $5 \mathrm{~min}$. & & 17 & " \\
\hline $\begin{array}{r}\text { Drew ..................... } \\
\quad \text { Phys. Rev., 17, p. 321, } 1903 .\end{array}$ & 90 secs. & 7 & 17.1 & “ \\
\hline $\begin{array}{r}\text { Porter } \\
\text { Astrophys. Jour., } 2 \mathbf{Q 2} \text {, p. 229, } 1905 .\end{array}$ & 906 & 3.6 & 27.5 & “ \\
\hline Coblentz $\ldots \ldots \ldots \ldots \ldots \ldots \ldots \ldots$ & 906 & $15(10 \times 1.5)$ & 8 to 10 & “ \\
\hline 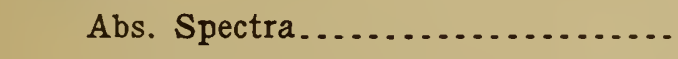 & 506 & 12 & 10 to 12 & “ \\
\hline $\begin{array}{c}\text { Phys. Rev., 16, } 20 \text {, and } 22 . \quad \text { (Vac. } \\
\text { tube.) } \ldots \ldots \ldots \ldots \ldots \ldots\end{array}$ & 100 " & $11(11 \times 1)$ & 52 & “ \\
\hline Another vane........... & 150 “ & 4.5 & 71 & " \\
\hline (This Bulletin, ibid.)... & $70 "$ & “ & 35 & " \\
\hline
\end{tabular}

3. Sensitiveness Compared with Wave-Length of Exciting Source.-In his investigations of emission spectra of the alkali metals, using a prism and lenses of quartz, and a bolometer, Snow ${ }^{22}$ found that the vapor of the carbon arc had the larger portion of its energy concentrated in one large band in the violet. The writer using a radiometer, a rock-salt prism, and a mirror spectrometer for investigating infra-red emission spectra, found that the radiometer gave small, if any, deflections in the violet. 'The violet band is far enough from the reflection minimum of silver

21 "Investigations of Infra-red Spectra;" I905.

${ }^{22}$ Snow, Phys. Rev., 1, pp. 28 and 221; I893. 
not to be weakened by it, hence it appeared that the radiometer might be selective in its behavior to radiant energy.

To test this point the following experiment was tried: 'The total radiation from the aluminum spark (with glass-plate condenser) on a 10,000 volt transformer was measured with a very sensitive radiometer (period 65 to 70 seconds, sensitiveness $35 \mathrm{~cm}$ per $\mathrm{mm}^{2}$ ) just described, and with a bolometer to be described subsequently. The window of the radiometer was of white fluorite $2 \mathrm{~mm}$ thick, hence transparent to the ultra-violet, but opaque beyond $r o \mu$. A large part of the energy of the aluminum spark lies in the ultra-violet. The maximum energy of the warm electrodes occurs at about $8 \mu$. The radiation from the spark passed through a quartz cell $8 \mathrm{~mm}$ thick, containing distilled water which absorbed the infra-red energy. The observations consisted in obtaining the ratio of energy transmitted by a glass plate $8 \mathrm{~mm}$ thick (which is opaque to rays shorter than $0.3 \mu$ ), to the total energy of the spark.

Unfortunately at the high sensitiveness required for measuring ultra-violet radiation the two instruments were not in perfect working order at the same time. During the first test the bolometer-galvanometer had a short period-ro seconds-and caused trouble by the drifting of the zero with changes in the spark, while in the second test the radiometer was leaking slightly, which caused its zero to drift. Then too the spark was by no means constant, but, as will be seen presently, the ratio above referred to is about the same for the radiometer and the bolometer, after correcting for the loss of 4 per cent by reflection at the fluorite window. The agreement is close enough to show that the radiometer is not selective in its action, and hence is adapted to investigations in the ultra-violet.

In the first test the direct radiation from the aluminum spark (with a condenser in parallel) was compared with the part transmitted by glass. There was some infra-red energy in this case, which made the ratio lower than in the second experiment. The direct deflections with the radiometer were about $20 \mathrm{~cm}$. The ratio of the deflection through plate glass to the direct deflection varied from $i 7$ to 19.5 per cent (mean about i 8 per cent), while with the bolometer the same ratio varied from 16 to 20 per cent, 
the mean being about 19 per cent. The bolometer followed the fluctuations of the spark, hence the greater variations. The spark was $75 \mathrm{~cm}$ from the radiometer and $25 \mathrm{~cm}$ from the bolometer. In the second test the infra-red radiation was absorbed by the cell of water, with quartz windows. Plate glass was again used to absorb the ultra-violet. In this test the average ratio of the radiation transmitted by the glass to the total radiation was about 65 per cent, while the same ratio for the bolometer was 67 per cent. Correcting for the loss by reflection at the window, the ratio for the radiometer would be about 69 to 70 per cent.

The results as a whole show that the radiometer is not selective, i. e., it is as efficient in the ultra-violet as is the bolometer.

4. The Radiometer Compared with the Bolometer.-In discussing the merits of the radiometer writers have generally emphasized the fact that it is not adapted for quantitative work, since it can not be calibrated. As a matter of fact, in reviewing the work done in radiation it was found that even with the bolometer there are only a few cases where the energy was obtained in absolute measure. Even in the study of the laws of radiation from a hollow enclosure, or Kirchhoff radiator (so-called "blackbody"), the galvanometer deflections were observed and reduced to a single standard of sensitiveness, which was in arbitrary units. The same can be done with the radiometer. Its sensitiveness is easier to control, since it can be made to depend only upon the pressure of the residual gas; whereas the constant of a galvanometer varies continually. It is not affected by magnetic variations, and a heavy vane is less affected by earth tremors than is a very light galvanometer suspension. It is sensitive to temperature changes, but less so than the bolometer, and it can be more easily shielded from temperature changes than can a bolometer with its galvanometer, battery, etc. The fact that it is not portable is not a serious drawback, since it is not usually necessary to move the instrument. It has two disadvantages, viz, its window, or preferably double window, is selective in its transmission, and its period is somewhat longer than that of a bolometer and galvanometer of equal sensitiveness. But the latter is nearly always drifting and to repeat one's readings takes as long for an observation as it does with a radiometer. Since the 
weight is of minor importance, tremors are avoided by having the suspension weigh about 8 to $\mathrm{ro} \mathrm{mg}$. When used with a good mercury pump it requires no attention after it is adjusted. A delicate galvanometer requires frequent adjustment and, in connection with a bolometer, the investigator's time is occupied principally with the care of the instrument (at least that has been the writer's experience), which should be a secondary matter. The two instruments are of the same order of sensitiveness, with the possibility of the radiometer being the more sensitive. This is well illustrated in the test for their efficiency to ultra-violet radiation, where both instruments were at about their maximum working sensitiveness. The bolometer used was $0.22 \times 10 \mathrm{~mm}$ in area, resistance $2.8 \mathrm{ohms}$, and for a bolometer current of 0.04 ampere, with a galvanometer sensitiveness of $i=\mathrm{I} .5 \times \mathrm{IO}^{-10}$ ampere (full period $=\mathrm{I} 6$ seconds), had a temperature sensitiveness of $9^{\circ} \times \mathrm{IO}^{-6}$ per $\mathrm{mm}$ deflection, on a scale at $\mathrm{I} \mathrm{m}$. (See Table IV.) A candle ${ }^{24}$ at I $\mathrm{m}$ gave a deflection of $45 \mathrm{~cm}$, which, on the assumption that the sensitiveness is proportional to the square root of the area of bolometer strip, is $30 \mathrm{~cm}$ per $\mathrm{mm}^{2}$. For the radiometer, having a vane $0.5 \times 9 \mathrm{~mm}$, a candle gave a deflection equivalent to $159 \mathrm{~cm}$ at $\mathrm{I} \mathrm{m}$, or, since the deflection is proportional to the area of the exposed vane, $35 \mathrm{~cm}$ per $\mathrm{mm}^{2}$ (Table IV). In other words, the radiometer was $\mathrm{I} .2$ times as sensitive as the bolometer, or I $\mathrm{mm}$ deflection corresponded to $7^{\circ} .5 \times 10^{-6}$. (For a full period of 2.5 minutes its sensitiveness was $3^{0} .8 \times \mathrm{IO}^{-6}$.) Its period, however, was 4.5 times that of the bolometer-galvanometer. This examination of sensitiveness is based on the assumption that the radiometer was as complete an absorber of energy as the bolometer. Judging from its period, its efficiency is much lower than that of a bolometer, hence the radiometer must be sensitive to temperature changes less than the value just given.

The sensitiveness of bolometers thus far attained is about ₹ $\overline{0} \frac{1}{0}-\overline{0} \overline{0} \overline{0}$ degree per $\mathrm{mm}$ deflection. Paschen (loc. cit.) claims a sensitiveness of $\overline{1} \overline{0}-\overline{0} \frac{1}{00} \overline{0} \overline{0} 0$ degree by reading to O.I $\mathrm{mm}$. But the conditions are rare when one can read to o. I $\mathrm{mm}$, so that the estimate would seem too high. As will be seen presently, the

\footnotetext{
${ }^{24} \mathrm{~A}$ Nernst-heater was also used in making the comparison.
} 


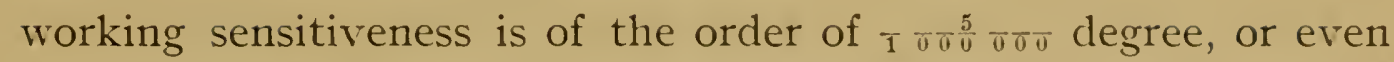
considerably less. The maximum sensitiveness is of course needed only in cases where the radiation is very weak.

5. Some Points in Radiometer Construction.-There is room for great improvement in radiometer construction. One must expect some difficulties in controlling instruments of great sensitiveness. There are always inequalities in the two sets of junctions of a thermopile, so that when it is first connected to a very sensitive galvanometer, the deflection must be brought back to its original point by adjusting the control magnets. The same is true of the very sensitive radiometers constructed by the writer. $^{21}$ On exhausting the instrument the deflection will move off the scale (deflection away from the window) and must be brought back by means of a torsion head. If the pump leaks there will be a drift toward the window. The deflection seems to be due to the inequality of the temperature of the window and the metal shield, back of which is the vane that remains unexposed.

By placing the vanes at a greater distance, 6 to $8 \mathrm{~mm}$, from the window, in the sensitive radiometer just described, it was found that the drift due to sudden changes in the temperature of the window was avoided and a torsion head was not needed. The use of a torsion head has been found necessary only in the most sensitive radiometer (deflection $=50 \mathrm{~cm}$ per $\mathrm{mm}^{2}$ ). The drifting of the zero is a far less serious matter than in a bolometer or a thermopile, and is not troublesome in less sensitive instruments.

The dimensions to be chosen for the vane will depend on its distance from the spectrometer slit. The image of the slit can be made to just cover the vane by placing a short focus (say io to I $2 \mathrm{~cm}$ ) condensing mirror between the spectrometer slit and the radiometer vane. Since mica vanes are not opaque to all rays, and since the lampblack may rub off, it is better to use platinum vanes, about $0.01 \mathrm{~mm}$ thick, blackened electrolytically and then smoked.

In addition to having the radiometer enclosed in a heavy metal case to shield it from temperature changes, it is advisable to cover the instrument with a metal cylinder and to pack wool between it and the inner case. In warm weather it has been found that the vanes become easily electrified from the mercury 
LI 4

Bulletin of the bureau of Standards.

[ $\mathrm{Vol} .4, \mathrm{AO} 0.3$.

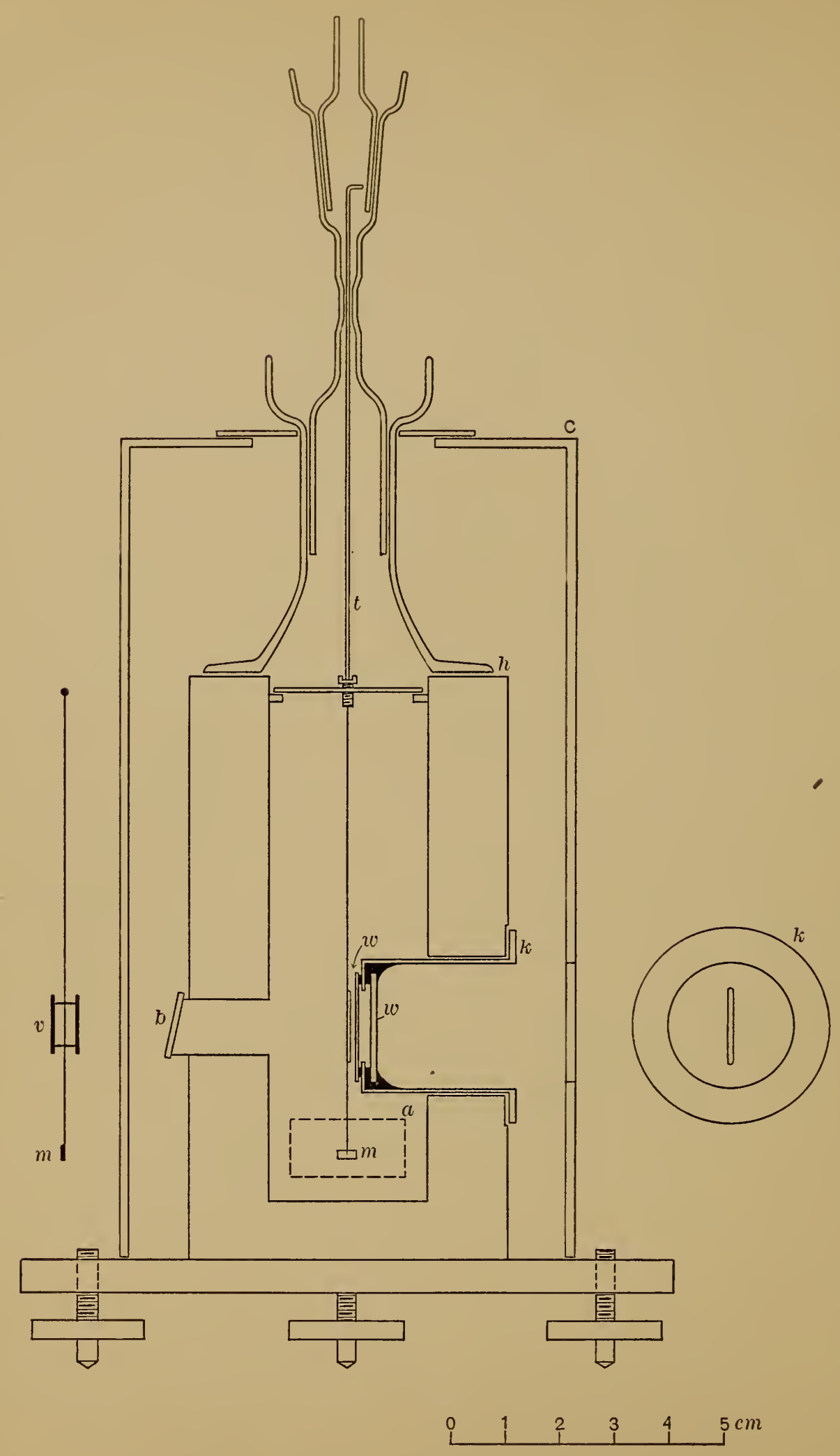

Fig. 4.-Radiometer. 
vapor. This is avoided by placing gold foil on cotton between the pump and the radiometer. This electrification effect is not well understood. It seems to be most noticeable when a fluorite window is used next to the vane. This does not always seem to be true, however, for in the ultra-violet radiation test just described there was but one window, with the metal slit on the outside and the vane inside, and no difficulty was experienced with electrification. Without disturbing the vane, a second fluorite window was placed inside the first one, hoping thus to avoid heat conduction. After several days' trial it was found impossible to prevent the vanes from being attracted to the inner window, even when covered with tin foil, and it was necessary to replace this window by rock salt. It is well known that plates of fluorite after being cut from a crystal are frequently under internal stresses; but whether this could produce sufficient polarity, as in the case of quartz, is not known. The freedom from electrification with rock salt may be explained on the assumption that it is hydroscopic and dissipates any electrical charges on its surface.

In spectrum energy work the best method of varying the sensitiveness of a radiometer is to use a sectored disk of variable aperture. The sensitiveness may also be varied by turning the leveling screw, which is in line with the windows $w . w$. in Fig. 4. The complete instrument is here shown, except the bulb containing gold foil on cotton. The figure is drawn to scale and needs but little explanation. The outer metal shield, $c$, is shown dotted. Between it and the heavy metal case is wool or hair felt. 'The double windows of rock salt or fluorite are shown at $w$. $w$. The torsion head, $t$, is self-explanatory, as is also the vane which is also drawn to scale. The viewing window, $b$, of glass, for adjusting the vane on the slit, as well as the glass window, $a$, for viewing the scale, are fastened permanently with melted shellac or "Khotinsky" cement. The joints at the top and at the rock salt window, $k, k$, are made with a mixture of beeswax and tallow, and painted with shellac, which has been found to make air-tight connection.

\section{THE BOLOMETER WITH ITS AUXILIARY GALVANOMETER.}

We have now to consider one of the most useful radiation meters yet devised, namely, the bolometer, which is simply a 
Wheatstone bridge, two arms of which are made of very thin blackened metal strips of high electrical resistance and high temperature coefficient, one or both of which are exposed to radiation. When thus exposed their temperature changes, thus unbalancing the bridge, and the resulting deflection of the galvanometer gives a measure of the energy absorbed. The maximum sensitiveness of the bolometer is limited by the size of the strip to be exposed to radiation. Any further gain in sensitiveness must be attained by increasing the sensitiveness of the galvanometer, which, for the moving magnet type varies approximately as the square of its period (undamped). The sensitiveness is also directly proportional to the bolometer current, but this is limited by the resistance of the bolometer strips. It will be noticed presently that the working sensitiveness of the various galvanometers thus far used is of the order of $2 \times 10^{-10}$ ampere per $\mathrm{mm}$ deflection, while the working temperature sensitiveness of the bolometer and galvanometer varies from $5 \times 10^{-5}$ degree to $5 \times 1 \mathrm{IO}^{-6}$ degree for $\mathrm{I} \mathrm{mm}$ deflection.

1. Historical Summary.-The various types of bolometer-galvanometer apparatus will first be noticed, in so far as they relate to spectro-radiometric work.

The first great step in improving the moving magnet galvanometer is due to Kelvin, who decreased the weight of the moving parts to a few milligrams, and introduced the astatic system of magnets.

The main problem in bolometer construction is to use strips of a metal having a high resistance-temperature coefficient, a small specific heat, and a low-heat conductivity. Such metals are nickel, platinum, tin, and iron, but, for various reasons in mechanical construction, platinum is the most commonly used. The manner in which this instrument was developed to its present high sensitiveness is best illustrated by considering the various designs of different investigators.

The pioneers in exact spectro-bolometric work are Langley, Angström, and Julius. While Langley was not really the first to discover the principle of the bolometer, he was the first to 
invent a practical instrument ${ }^{26}$ and demonstrate its superiority to all other radiation meters for accuracy, quickness of action, and adaptability. His improvements of the instrument extend over a long period, and it will be sufficient to say that whereas his first instrument had a temperature sensitiveness of $0.000 \mathrm{O} 2$ per $\mathrm{mm}$ deflection of the galvanometer, the latest recorded a temperature change of 0 :ooo oo I per $\mathrm{mm}$ deflection, when used with a galvanometer having a figure of merit of $i=5 \times \mathrm{IO}^{-10}$ ampere. For his solar radiation work the bolometer strips are about I $2 \mathrm{~mm}$ long, 0.05 to $0.2 \mathrm{~mm}$ wide, and have a resistance of about 4 ohms. The wire is obtained as "Wollaston wire" of o. I mm diameter inclosing a platinum core of 0.0125 $\mathrm{mm}$. This is flattened by hammering, after which the silver is dissolved in nitric acid. He found that a thickness of less than $0.002 \mathrm{~mm}$ is inadvisable, thinner ones being disturbed mechanically by air currents. The current used was about 0.03 ampere. The galvanometer generally used at the Astrophysical Observatory has I. $6 \mathrm{ohms}$ resistance. The bolometer strips are of platinum, while the balancing resistances are of platenoid, which is practically the same as German silver. It was finally found that the maximum sensitiveness ${ }^{27}$ of the bolometer circuit is closely approximated when the balancing coils are upwards of 4 times the resistance of the bolometer strips, and the galvanometer resistance is not less than 0.6 or more than 4 times the resistance of the bolometer strip. The bolometer strips, balancing coils, and slide wire adjustment are all enclosed in a double-walled chamber, which eliminates accidental drift of the galvanometer needle. The whole outfit is in a room which can be maintained at a constant temperature. This has reduced the drift to a minimum.

The published details of some of the more important bolometers and accessory apparatus used in radiometric investigations are summarized in the following table (Table IV):

${ }^{26}$ Langley, Proc. Amer. Acad., 16, p. 342; r88r. Chemical News, 43, p. 6; r88. ${ }^{\circ}$ British Assoc. Report, 1894, (o:000 oor) Annals. Astrophys. Obs., 1.

${ }^{27}$ Abbot, Astrophys. Jour., 18, p. I; 1903. 


\section{TABLE IV.}

Bolometer-Galvanometer Sensitiveness.

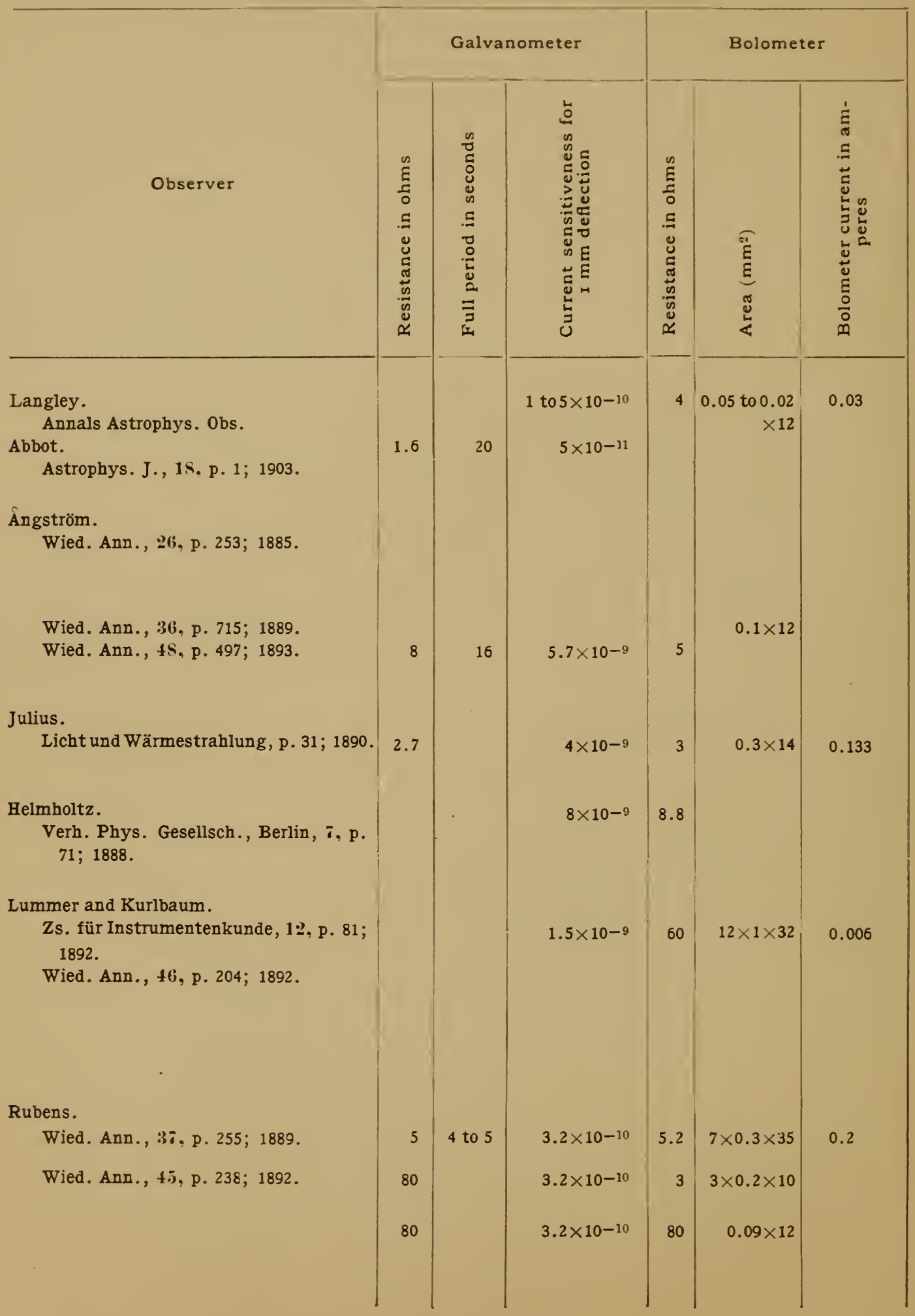


TABLE IV (continued).

Bolometer-Galvanometer Sensitiveness.

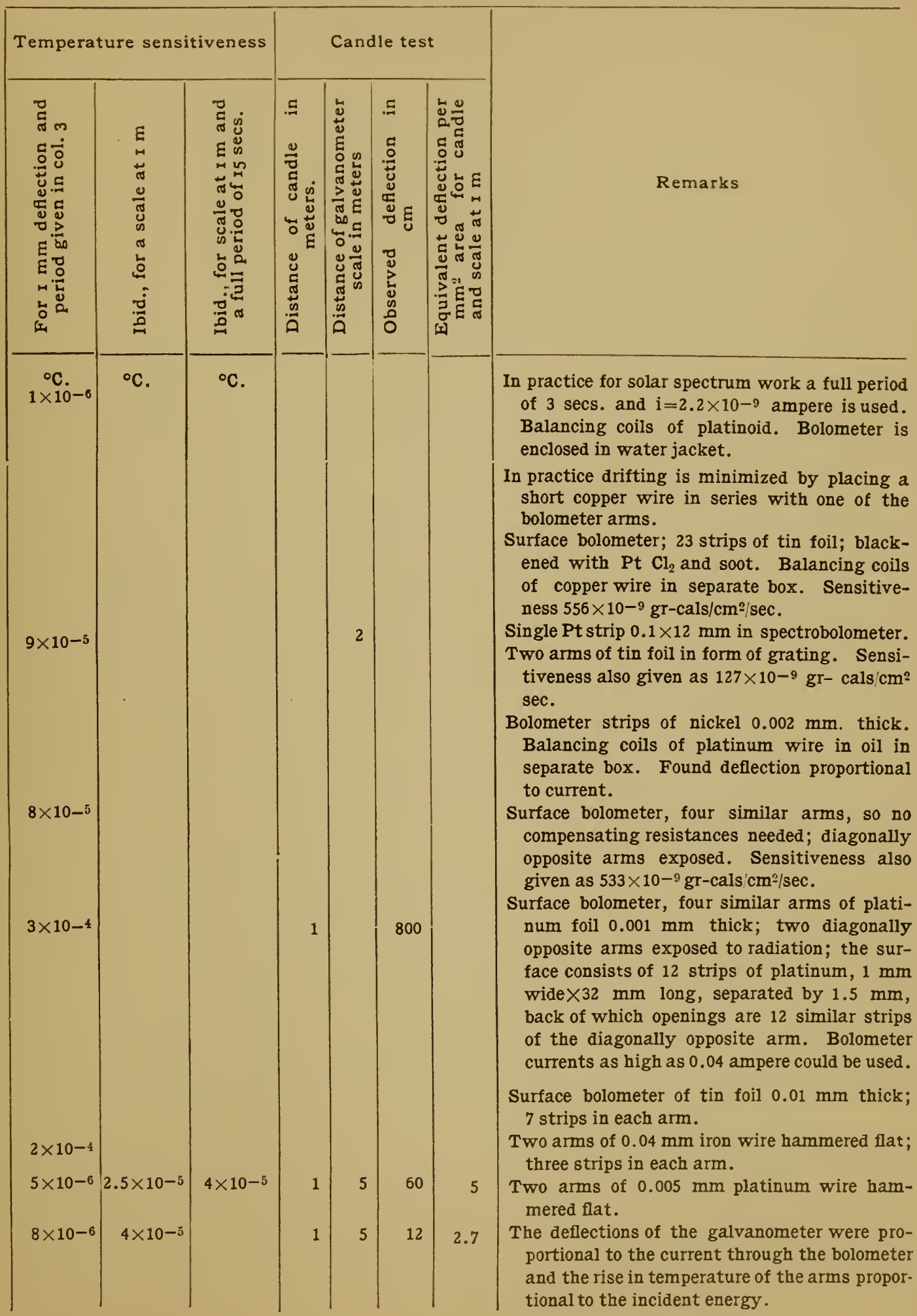


TABLE IV-Continued.

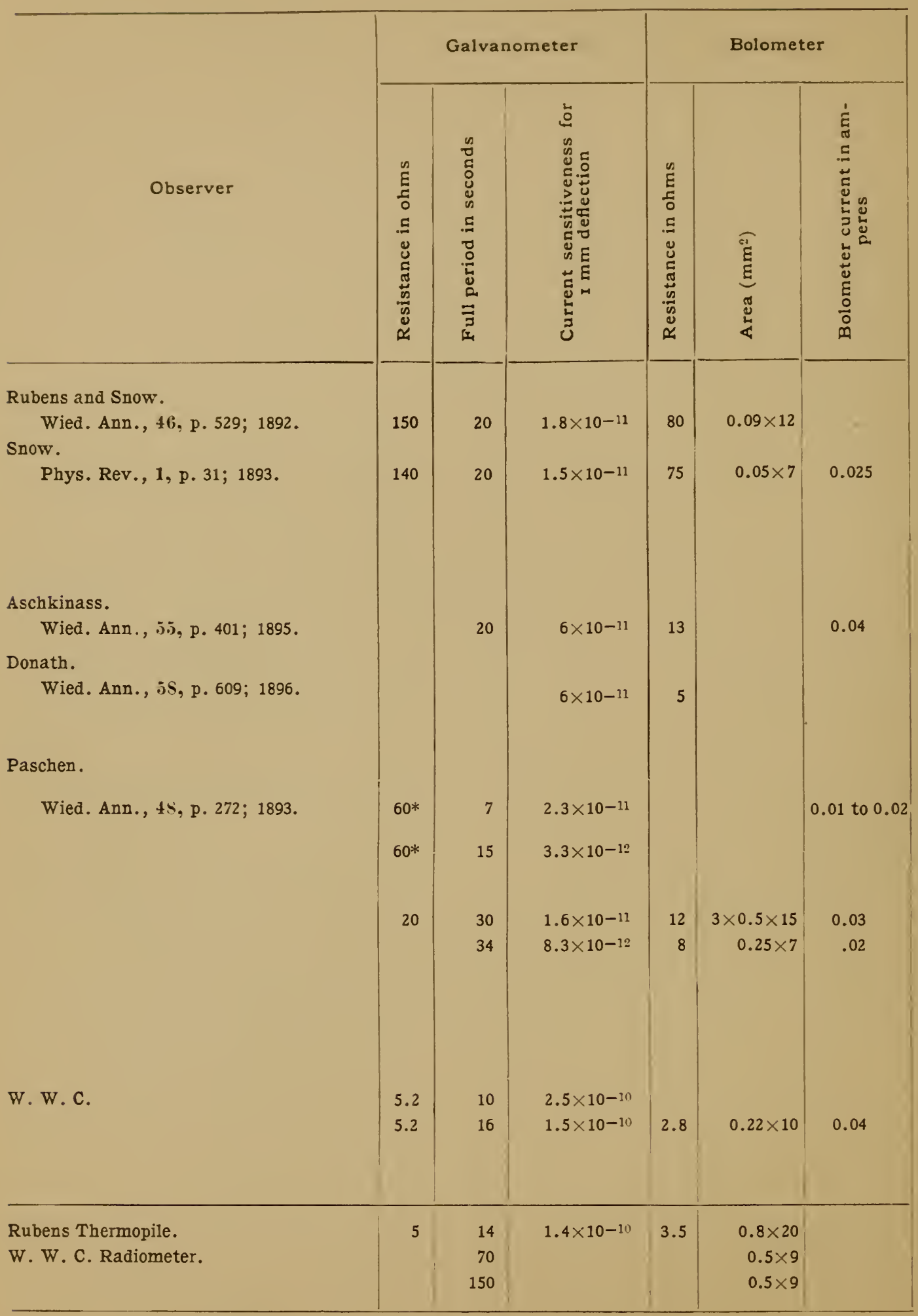


TABLE IV-Continued.

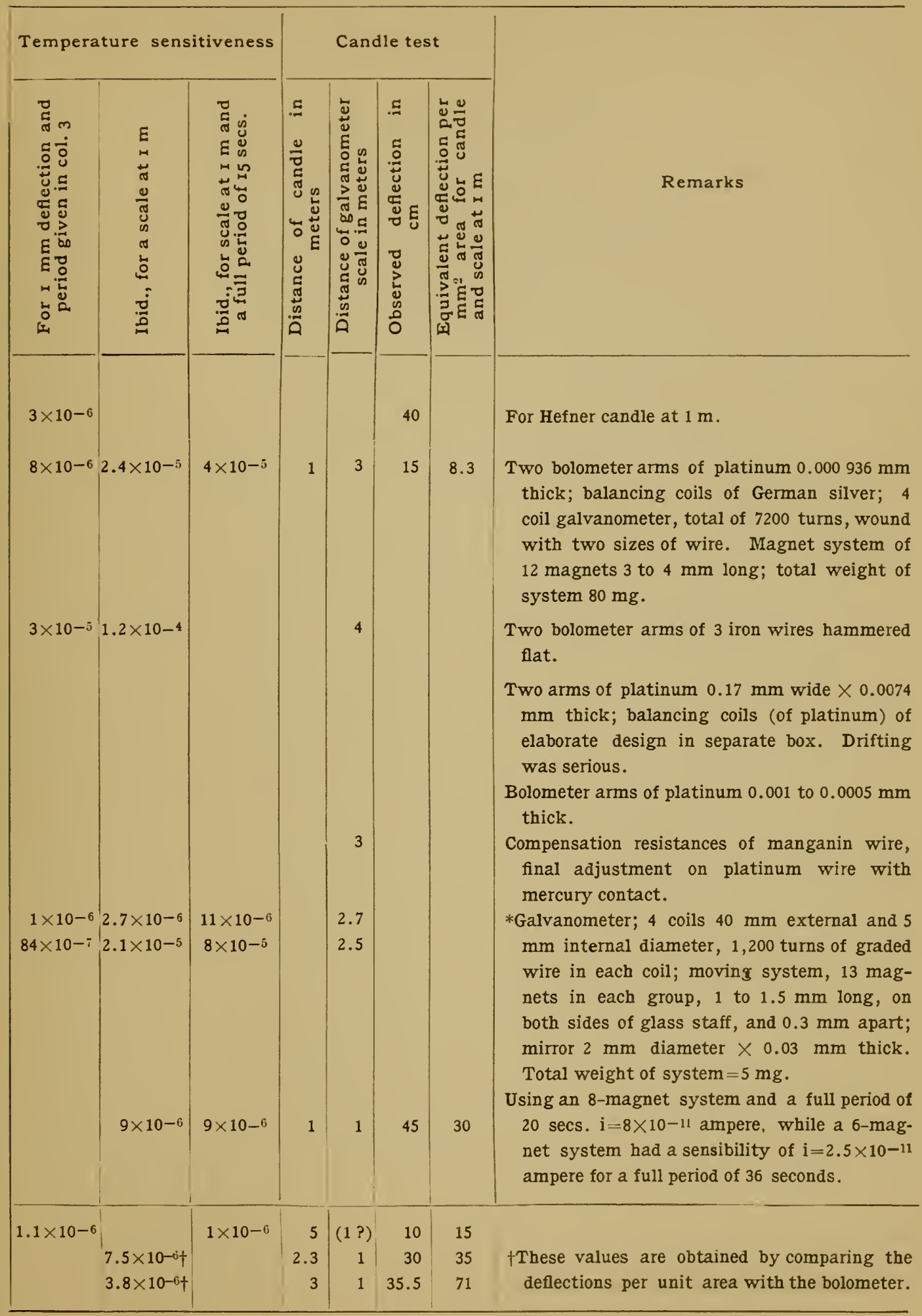


L ummer and Kurlbaum ${ }^{28}$ improved the design of the surface bolometer by using thin platinum foil (o.oor mm. thick) and making the arms of high resistance by a special grid construction, by selecting four arms of as nearly the same resistance and temperature coefficient as possible, and by exposing two diagonally opposite arms to the radiation. Snow ${ }^{29}$ was among the first to give much attention to the possible gain in sensibility by the use of a more sensitive galvanometer. Paschen ${ }^{30}$ continued the work in this direction and constructed the most sensitive galvanometer used up to that time. By the use of very light magnet systems and a long working period (as much as 30 secs.) a marked increase in sensibility was attained. He adds that for a full period of 40 seconds and a battery current of 0.06 ampere through his bolometer, by reading to o. I $\mathrm{mm}$, it would have been possible to detect 0.000 ooo $\mathrm{I}$. However, such a long period and large battery current is not practicable, so that the last estimate of temperature change has little meaning. Even for a full period of 20 seconds the magnetic and thermal disturbances are generally sufficient to interfere with bolometric work, and a fair estimate of the sensi-

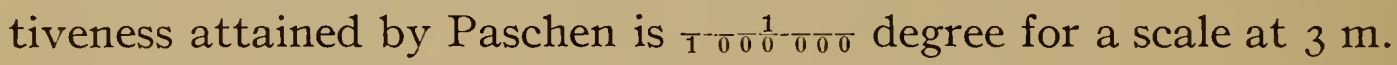
In the Astrophys. Jour., 3, p. 24, I 896, he gives a practical example of the sensitiveness of his bolometer. The complete period of his galvanometer was 34 seconds and for a scale at $2.5 \mathrm{~m}$ the sensitiveness was $i=8.3 \times \mathrm{IO}^{-12}$ ampere. With a current of 0.02 ampere through the bolometer (dimensions $=0.25 \times 0.0005 \mathrm{~mm}$; resistance $=8 \mathrm{ohms}$ ), a deflection of I $\mathrm{mm}$ corresponded to a difference in temperature of $84^{\circ} \times \mathrm{IO}^{-7}$, or $2^{\circ} . \mathrm{I} \times \mathrm{IO}^{-5}$ for a scale at $\mathrm{I} \mathrm{m}$. This sensitiveness was attained in the present work for a very much shorter period but higher current. Paschen appears to have been the first to use manganin wire in his balancing coils and a heavy platinum wire with a mercury contact for the final compensation, all of which were in a separate wooden box.

From this historical record it will be noticed that a fair estimate of the temperature sensitiveness of the various instruments is about $5^{\circ} \times \mathrm{IO}^{-6}$ for $\mathrm{I} \mathrm{mm}$ deflection on a scale at a distance of $\mathrm{I} \mathrm{m}$.

${ }^{28}$ Zs. für Instrumentenkunde, 12, p. 8I; I 892. Wied. Ann., 46, p. 204; I892.

${ }^{29}$ Phys. Review, 1, p. 31 ; 1893.

30 Wied. Ann., 4S, p. 272 ; 1893. 
Most instruments cited fall far below this value; but the cases are exceptional where so great a sensitiveness is needed. For measuring radiation at low temperatures, or for vacuum tubes, or for the examination of the remote ends of the spectrum this great sensitiveness is required. It is a significant fact that the bolometer with its long period galvanometer has not been used for such work. Here the Rubens thermopile is the most serviceable and reliable.

Mendenhall and Waidner ${ }^{31}$ constructed a sensitive galvanometer of 4 coils, having an external diameter of $15 \mathrm{~mm}$, internal diameter $2 \mathrm{~mm}$, wound with six sizes of wire, 500 turns in each coil. The resistance (with coils in parallel) was 3 ohms. They used 3 magnets in each group, lengths = I.I $5 \mathrm{~mm}$, total weight of suspension system I $\mathrm{mg}$, and attained a sensitiveness of $i=5.6 \times$ $\mathrm{IO}^{-11}$ ampere for a full period of 9 seconds and scale at 2 meters distance, or $\mathrm{I} . \mathrm{I} \times \mathrm{IO}^{-10}$ ampere at $\mathrm{I}$ meter.

Abbot ${ }^{32}$ built a 16 coil instrument which had a resistance of $\mathrm{I} .6$ ohms. The sensitiveness was $i=5 \times 10^{-11}$ ampere for a complete period of 20 seconds and scale at I meter. However, to increase the steadiness of the needle for solar-energy spectra the full period is reduced to only 3 seconds. Assuming that the deflection is inversely proportional to the square of the time of single swing (true only for low air pressures) the sensitiveness is $i=2.2 \times \mathrm{IO}^{-9}$ ampere for a full period of 3 seconds.

Ingersoll ${ }^{33}$ has recently constructed a sensitive galvanometer similar to the one described by Mendenhall and Waidner (loc. cit.). The galvanometer has 4 coils of $20 \mathrm{ohms}$ each, I $6 \mathrm{~mm}$ outside and $2 \mathrm{~mm}$ inside diameter; weight of suspended system less than $2 \mathrm{mg}$. The highest sensitiveness attained was $4 \times 10^{-11}$ ampere for $5 \mathrm{ohms}$ resistance and scale at $1.5 \mathrm{~m}$, but lack of steadiness and proportionality of deflection led him to reduce the sensitiveness to $2 \times \mathrm{IO}^{-10}$ ampere per $\mathrm{mm}$ deflection with a 10 second period for ordinary usage. His bolometer was $0.5 \times 8 \mathrm{~mm}$, and at highest sensitiveness a candle at I $\mathrm{m}$ gave a deflection of $200 \mathrm{~cm}$ on the galvanometer scale at a distance of 1.5 meters. His balancing coils are of "IA" wire, which is practically the same composition as "con-

${ }^{31}$ Mendenhall and Waidner, Amer. Jour. Sci., 27, p. 249; 190 r.

32. Abbot, Astrophys. Jour., 1S, p. 1; ig03.

${ }^{33}$ Ingersoll, Phil. Mag. (6), 11, p. 4 I ; 1906.

$15298-08-6$ 
stantan" or "advance" and hence, like German silver or platenoid, is subject to thermoelectric disturbances.

2. The Construction of Sensitive Galvanometers.-One of the best known sensitive galvanometers on the market is the du BoisRubens ${ }^{34}$ type. 'This instrument is magnetically shielded by enclosing the coils within two spherical shells of iron. There are two coils of about $6 \mathrm{~cm}$ external diameter. Two magnet systems are furnished with the galvanometer. The heavy system, which has a large mirror, has 14 magnets about $7 \mathrm{~mm}$ long arranged on both sides of an aluminum staff. The lighter one has ro magnets about $4 \mathrm{~mm}$ long. The galvanometer tested by the writer was found to give deflections proportional to current for deflections as large as $30 \mathrm{~cm}$, which is often an important item. The large weight of the moving system is of some importance in places where there are severe mechanical disturbances. In this galvanometer with the two coils in parallel, resistance $=2.85 \mathrm{ohms}$, using the complete magnetic shield and the heavy system of magnets, the sensitiveness was $i=4 \times 10^{-10}$ ampere for a full period of 6 seconds and circular scale at $I$ meter. Using the light system and a full period of 6 seconds, the sensitiveness was only $i=7 \times 10^{-8}$ ampere, even after it was remagnetized. But in both cases, and especially with the light system, the zero kept shifting back and forth continuously, so that its maximum working sensitiveness was limited to this value. On the other hand, the galvanometer with short magnets, to be described presently, shielded with only one cylinder of iron, situated close beside the du Bois-Rubens galvanometer and tested at the same time, had a perfectly steady zero, even for three times this period, when its sensitiveness was $i=1.5+1 \mathrm{O}^{-10}$ ampere. In the latter instrument, however, the coils are small and the proportionality between current and deflections does not hold for deflections greater than ro to $12 \mathrm{~cm}$; but, since a shunt must be provided anyway, the deflection can be kept within these limits so that this is not a serious objection. A four-coil galvanometer, also due to du Bois and Rubens, ${ }^{35}$ which has been much used abroad, may be obtained on the market.

${ }^{34}$ Du Bois and Rubens, Ann. d. Phys. (4) 2, p. S4; 1900.

${ }^{35} \mathrm{Du}$ Bois and Rubens, IVied. An1., 4S, p. 236; IS93. 
This is a much larger instrument, of the Thomson astatic type, than the one described above and is not adapted to magnetic shielding. The instrument is furnished with two sets of four coils, of $20 \mathrm{ohms}$ and $2000 \mathrm{ohms}$ each, respectively, and three magnet systems of $\mathrm{I} 500,250$, and $100 \mathrm{mg}$, respectively.

In this country the type of small-coil galvanometer just mentioned is being very generally adopted, although it is not to be obtained in the market. The question of the best form of coils, size of wire, kind of magnets, etc., has been thoroughly discussed by Mendenhall and Waidner, ${ }^{36}$ and by Abbot, ${ }^{37}$ so that little need be said on that subject. However, the manner of assembling the different parts into a small space for convenience in magnetic shielding and at the same time leaving the suspended system open to view (but shielded from air currents) seemed to admit of further improvement. The following design of an easily shielded galvanometer is the result of a study of previous types, and while it can not claim any new principles, the simplifications may appeal to the reader. Further simplifications are possible by changing the position of the binding posts to the base of the instrument, when the shield of Swedish iron (Fig. 6) can be brought closer to the coils. Labor in construction may be saved by imbedding the coils in paraffin instead of mounting them on insulated supports. Since the proximity of the upper and lower pairs of coils increases the deflection of the needle, they should be close together, and the control magnets should be on a long rod extending above or below the coils.

(a) Form of Coils.-The proper form and method of winding galvanometer coils to secure a maximum effect from a given weight or resistance of copper has been thoroughly discussed by Maxwell. ${ }^{38}$ He shows that the greatest effect is obtained by winding the coil with different sizes of wire, beginning with the smallest size, and by winding each layer so that it lies within the surface the polar equation of which is $r^{2}=d^{2} \sin \theta$, where $r$ is the length of the radius making an angle $\theta$ with the axis of the

\footnotetext{
${ }^{36}$ Mendenhall and Waidner, Amer. Jour. Sci., 12, p. 249; I9oI.

${ }^{37}$ Abbot, Astrophysical Jour., 18, p. I, I903. A nnnals Astrophys. Obs., 1, p. 246, etc.

${ }^{38}$ Maxwe11, Electricity and Magnetism, II, p. 360.
} 
coil, and $d$ the value of $r$ when $\theta=90^{\circ}$. Abbot (loc. cit.) has computed the most efficient coils satisfying these conditions, and gives a large table of results for coils wound with a single wire and for coils wound with three sections of wire of different diameters. He found that the total force exerted at the center is closely proportional to the 0.45 power of the total resistance and that coils composed of three sections of best sizes of wire give about 1.4 times the force of a coil of the best single size of wire of the same total resistance. In his best 25-ohm coil, wound in three sections, the diameters of the wires are $0.08,0.16$, and $0.32 \mathrm{~mm}(\mathrm{~B}$ and $\mathrm{S}$ size 40, 34, and 28). The lengths are 256, IO3I, and $4144 \mathrm{~cm}$, respectively, while the external diameter of the complete coil is $3.3 \mathrm{~cm}$.

In the present design the coils (20 ohms each) were computed for three sections of B and S gauge, Nos. 40, 36, and 30 wire, but were finally constructed of Nos. 40, 36, and 32, diameter of wire 0.07 , 0.127, and 0.199 mm, and lengths I.9, $4 . \mathrm{I}$, and $\mathrm{I} 2.3 \mathrm{~m}$, respectively. The external diameter of the coils is $18 \mathrm{~mm}$, the internal diameter $2 \mathrm{~mm}$. The wire was covered with a single layer of white silk insulation.

The mandrel described by others for winding the coils did not prove strong enough and a new one was devised. It is given full size in Fig. 5; the dotted ${ }^{38 a}$ lines indicate the method of winding the sections. To prevent the wires from slipping it is necessary to apply a dilute solution of shellac while winding. To make the coils rigid they are boiled in carnauba wax until the air bubbles are all expelled. ${ }^{39}$ Some of the shellac will come out in boiling. After the coil has cooled the nut is taken off and the plate of the mandrel is warmed and removed. On warming the heavy metal end of the mandrel the coil drops off. However, there is a tendency for the shellac to adhere to the plate and to the cone of the mandrel, and it is well to cover these parts with a thin layer of carnauba wax or paraffin before winding the coil. In winding the coils the ends of all the sections are brought out and soldered

\footnotetext{
${ }^{38 a}$ By accident the lines are drawn full instead of broken ones.

${ }^{39}$ This wax has a high coefficient of expansion and cracks on cooling, so that the writer prefers refined paraffin, which is easier to work and there is less likelihood of charring the silk insulation.
} 


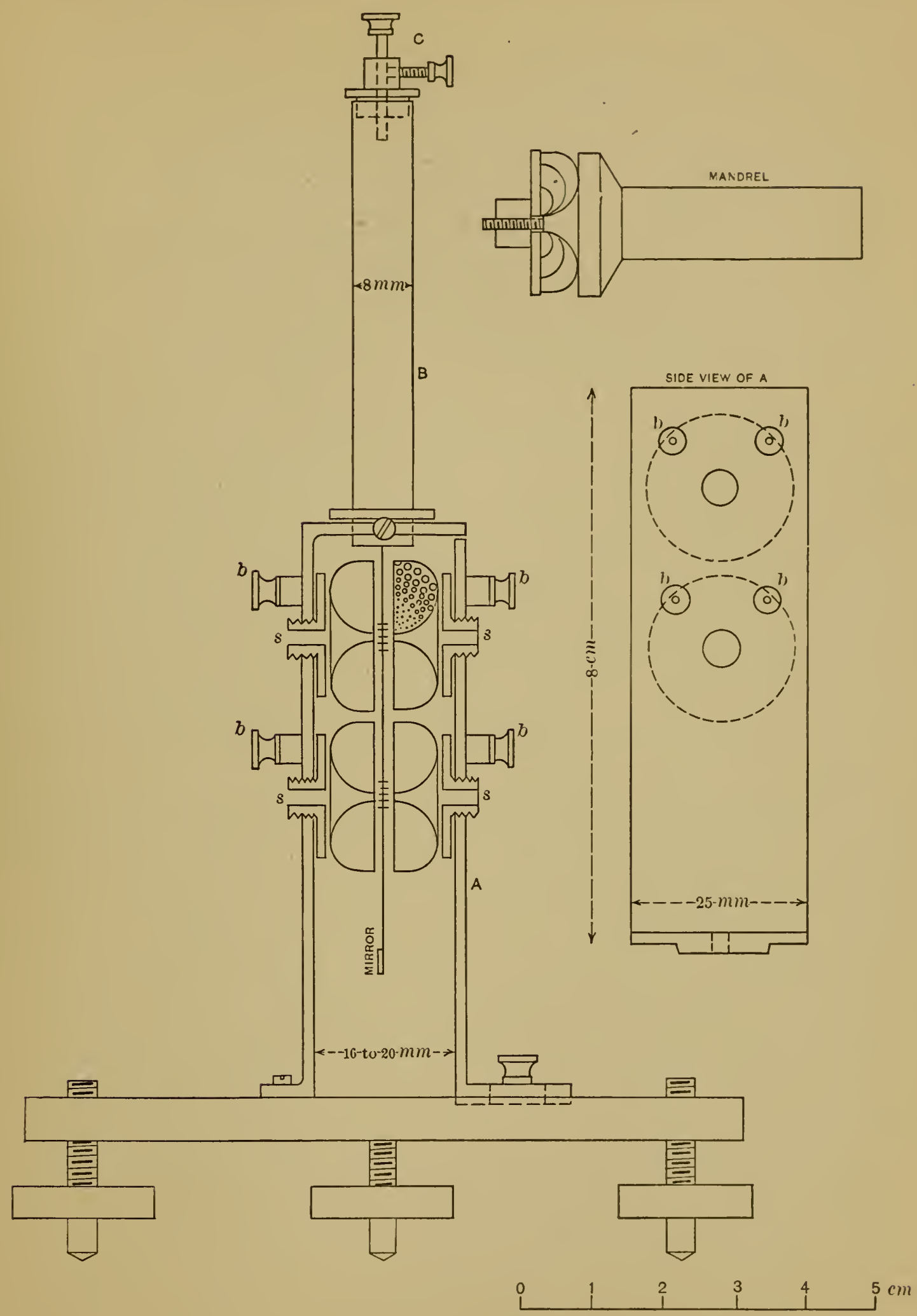

Fig. 5.-Galvanometer. (In the mandrel the curves should be dotted.) 
together (in series) at the back of the coil. It is important to use pure copper wire covered with a single layer of white silk. 'To avoid static charges of electricity it is customary to cover the coil faces with tin foil or gold leaf. A free space of at least a millimeter between the coil faces is necessary. (See Nichols, "The Galvanometer.")

(b) The Needle System.-The best dimensions and construction of the needle system has been extensively investigated by Paschen, by Mendenhall and Waidner, and by Abbot. In any magnet system the greatest sensibility is attained when the ratio of the magnetic moment to the moment of inertia of the system is a maximum. For two systems of magnets otherwise equal, if the magnets of one are $n$ times shorter than the other then its moments of inertia is $n^{3}$ times smaller than the other. The result is that the one with the shorter magnets will give $n^{2}$ times the deflection of the first, ${ }^{40}$ if the two systems be astaticised to the same period. However, Mendenhall and Waidner (loc. cit.) have shown that it is possible to use too short magnets. In their graphs of sensitiveness and length of magnets there is a decided maximum for a length of I.I mm. It has been found that magnets about $\mathrm{I}$ to I. $2 \mathrm{~mm}$ long, $0.2 \mathrm{~mm}$ wide, and 0.08 to $0.1 \mathrm{~mm}$ thick are very efficient.

During the course of the present investigation it was suggested that a more sensitive instrument would be produced (irrespective of period) by using a suspended system composed of many magnets. A system was constructed containing 20 magnets ( 10 in each group, 5 on each side of the staff) of the same size and kind of material as a Io-magnet system (5 magnets in each group) previously employed. This system, although made with the greatest care, proved to be far less satisfactory than those having less magnets. It was found that it made but little difference whether the system was composed of 6 (weight $5 \mathrm{mg}$ ), Io, or 20 (weight ro $\mathrm{mg}$ ) magnets, and, as will be noticed in the references just quoted, this appears to be the general experience; that is to say, one can deduce theoretically the best proportions for the magnet system, but their realization is limited by mechanical

${ }^{40}$ If the magnetic moment of the magnets varied directly as their length, which is not the case. 
difficulties. Of course, in the heavier systems the period will be longer for a given sensitiveness; but the better the astaticism the higher the attainable working sensitiveness, while the fewer the magnets the easier it is to get them into the same plane. This is most easily done by fastening them in place with a sugar solution on a piece of ground plate glass on which the dimensions of the system are marked in pencil. The glass staff is then attached by means of shellac, which is allowed to dry (touch with a hot wire), when the system is loosened from the glass by means of hot water. The system is magnetized in a double electro-magnet in the form of a $\sqsubset コ$ the intensity of magnetization being 1000 to 2000 lines per $\mathrm{cm}^{2}$.

In the present experiment the magnets were made from a bar of tungsten steel, which was cut into thin sections of about $0.008 \times$ $\mathrm{I} \times 2 \mathrm{~cm}$. These thin plates were then cut into strips 0.1 to 0.2 $\mathrm{mm}$ wide, and hardened, glass hard, by heating them to a red heat on an iron plate and plunging them into water. Although they were not tempered afterwards, they showed no marked change in astaticism on standing for several months. The lengths of the magnets were from 1.0 to $1.2 \mathrm{~mm}$. The mirror was of thin microscope cover glass about $1.5 \times 2 \mathrm{~mm}$.

Astaticising the system is apparently a simple operation, but in practice it is found otherwise. The system is suspended in a glass tube and by means of a magnet of known polarity it is determined which group in the system is the stronger. The latter is then weakened by bringing a like pole (use a weak magnet or a steel knitting needle) near it. In the same manner the weaker group of magnets is strengthened by bringing a strong unlike pole near to it. It is quite impossible to make the two sets of magnets so perfect that their planes will be parallel, so that in astaticising the two sets of magnets will be of equal strength when the system points east and west. The complete period may then be as long as 6 to ro seconds, although the latter is rarely attainable with such light systems. Since the magnets are mounted with shellac, which is hydroscopic, it is possible that the change in astaticism is due to a variation in humidity. 'This might be avoided by using refined paraffin in mounting the magnets. The finest quartz fiber must be used, viz, such that the 
suspension head may be turned through several revolutions without deflecting the astaticised needle by more than a few scale divisions.

(c) The Assembled Galvanometer.-The galvanometer without the shields is drawn to scale in figures 5 and 6 , and needs but little explanation. The side, $A$, is adjustable for admitting the magnet system. The coils are fastened to the ebonite supports by means of soft wax (a mixture of Venice turpentine and beeswax which hardens on standing). This permits an easy adjustment of the faces of the four coils to parallelism by simply inseting a piece of plate or microscope glass between them. The coils are then made vertical by means of the tripod screws. The needle system, shown at right angles to the coils, is then centered by tilting the tube, $B$, which is held to the frame by means of a screw, and can be lifted off at will. The top, $C$, can also be removed for mounting the fiber. The sides of the galvanometer are covered with microscope section glass, secured by soft wax. This prevents disturbances due to air currents, and at the same time admits excellent illumination of the interior. The ebonite supports and the binding posts may be omitted entirely by way of further simplifications. The coils are then mounted in paraffin, which provides the insulation.

(d) Sensitiveness of Galvanometer.-Using the ro-magnet system (weight about $5 \mathrm{mg}$ ), 5 magnets in each group, separated $0.4 \mathrm{~mm}$, with the mirror between the coils, the sensitiveness for a full period of 9 to Io seconds was $i=2.5 \times 10^{-10}$ ampere, and for a full period of $\mathrm{I} 8$ seconds $i=\mathrm{I} .5 \times \mathrm{IO}^{-10}$ ampere, the scale being at I meter. The sensitiveness of the 20 magnet system was only $i=3 \times 10^{-10}$ ampere for a full period of 20 seconds, while an 8-magnet system ( 4 in each group) had a sensitiveness of $i=$ $8.9 \times 10^{-11}$ ampere per $\mathrm{mm}$ deflection for the same period, 20 seconds. A light, 6-magnet system had a sensitiveness of $i=$ $2.5 \times 10^{-11}$ ampere for a full period of 36 seconds. The deflection was aperiodic (i. e., there was only one turning point) for a full period greater than 8 seconds. The resistance for the four coils in parallel was $5.23 \mathrm{ohms}$ at $20^{\circ}$.

This is not the highest attainable working sensitiveness, since the faces of the coils were separated about $2.5 \mathrm{~mm}$ to avoid the 
effects of static charges which may be troublesome in a newly mounted suspension. However, after the magnetic shields were in place and the instrument was adjusted, it was not disturbed in order to make the final test. By placing the mirror above or below the coils, and thus bringing the upper and lower pair of coils closer together (I $\mathrm{mm}$ is about the limit) a greater sensitiveness would (theoretically) have been possible. In a subsequent test, however, it was found that bringing the upper and lower pairs of coils closer together had but little if any effect in increasing the sensibility. In fact a high sensibility, for a given period, depends more upon the lightness and the perfection of the needle system. The glass (or quartz, which, however, is more brittle) staff must be straight, to avoid an increase in the moment of inertia of the suspension system. Mendenhall and Waidner (loc. cit.) show that for a badly constructed system, in which the axis of rotation departs $0.2 \mathrm{~mm}$ from the staff at its upper extremity, the sensibility will be decreased by 25 per cent. By using a gal-

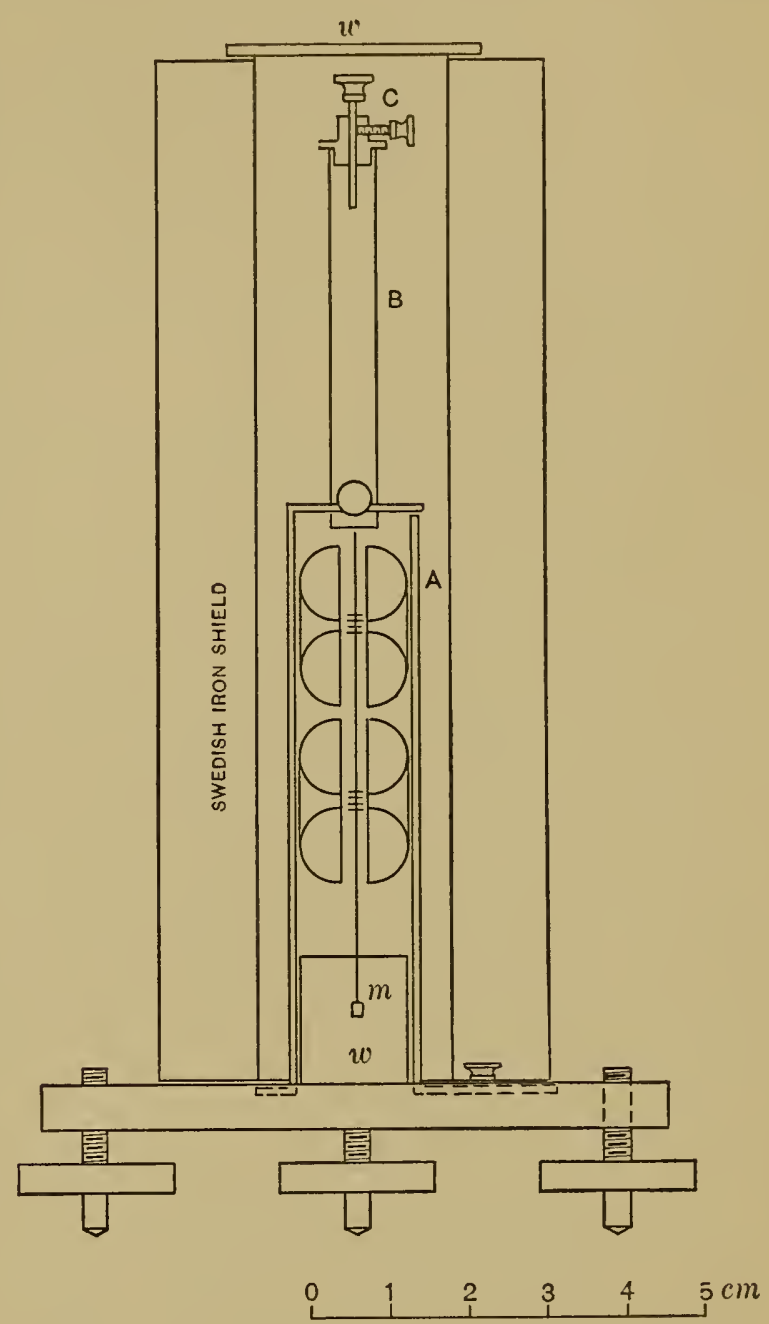

Fig. 6.-Galvanometer with inner magnetic shield. vanometer having small coils the glass staff will be short and easily drawn straight, while the complete system will be light. The glass rod may be straightened, after being drawn, by suspending it with a weight at one end, and heating it with a gas flame, or by simply heating a heavy glass rod until it is melted, and permitting one end to draw out the fiber by means of gravity. 
Where there are serious mechanical disturbances it is advantageous to use heavy systems. Since such disturbances are often encountered and elaborate galvanometer supports have to be provided, it may be noted that frequently the disturbance (tremors) is local, and that by selecting a different part of the same room the ill effects may be avoided. As a practical example the present galvanometer was very unsteady on a massive wall bracket; but by placing the galvanometer on a heavy box in the same place upon this bracket, the tremors were entirely eliminated.

The sensitiveness of a galvanometer (undamped) is approximately proportional to the square of the period. In the present tests the sensitiveness was found to be quite approximately proportional to the period, due to the air damping of the light magnet systems.

(e) Proportionality of Galvanometer Deflections. - It is desirable to have the proportionality of the galvanometer deflections to hold throughout a long range, and an attempt was made to attain this end.

From the various sizes of galvanometer coils mentioned in which about the same sensitiveness was attained, irrespective of the size of the coil, the writer concluded to use coils larger than $2 \mathrm{~cm}$ diameter, e. g., $3 \mathrm{~cm}$ to $4 \mathrm{~cm}$ diameter, in which the proportionality of current to galvanometer deflections ought to hold for deflections as large as 15 to $18 \mathrm{~cm}$. The magnets would be the same length, I to I. $2 \mathrm{~mm}$, as in the small coils (cf. Paschen, who used coils $4 \mathrm{~cm}$ diameter, magnets $1.5 \mathrm{~mm}$ long, and found the proportionality to hold for large deflections). To test this conclusion two additional galvanometers, having coils of 6 and 20 ohms, respectively, were constructed. The 6-ohm coils were wound with three layers of 2 ohms each, using $\mathrm{B}$ and $\mathrm{S}$ gauge Nos. 38,30 , and 26 wire, single covered white silk insulation, diameter of bare wire 0.IOI, $0.255,0.405 \mathrm{~mm}$, lengths 92,595 , and $1375 \mathrm{~cm}$, respectively. The complete coil was $2.8 \mathrm{~cm}$ diameter and $7 \mathrm{~mm}$ through its thickest part. The $20-0 h m$ coils were wound in three sections of equal resistance using B and S gauge Nos. 40,34 , and 28 , diameters of wire $0.080,0.160$, and $0.32 \mathrm{Imm}$, lengths $\mathrm{I} 90,770$, and $3080 \mathrm{~cm}$, respectively, and were $3.2 \mathrm{~cm}$ in diameter. Using $\mathrm{B}$ and $\mathrm{S}$ gauge 
Nos. 38,34 , and 30 , lengths 310,770 , and $2000 \mathrm{~cm}$, a coil $2.6 \mathrm{~cm}$ diameter is produced.

The relations between the currents through the galvanometers and the corresponding deflections are shown in Fig. 7. Curve $a$, for the small coil (four $20-0 h m$ coils in parallel, $18 \mathrm{~mm}$ diameter, magnets I mm long) galvanometer shows that the deflections are

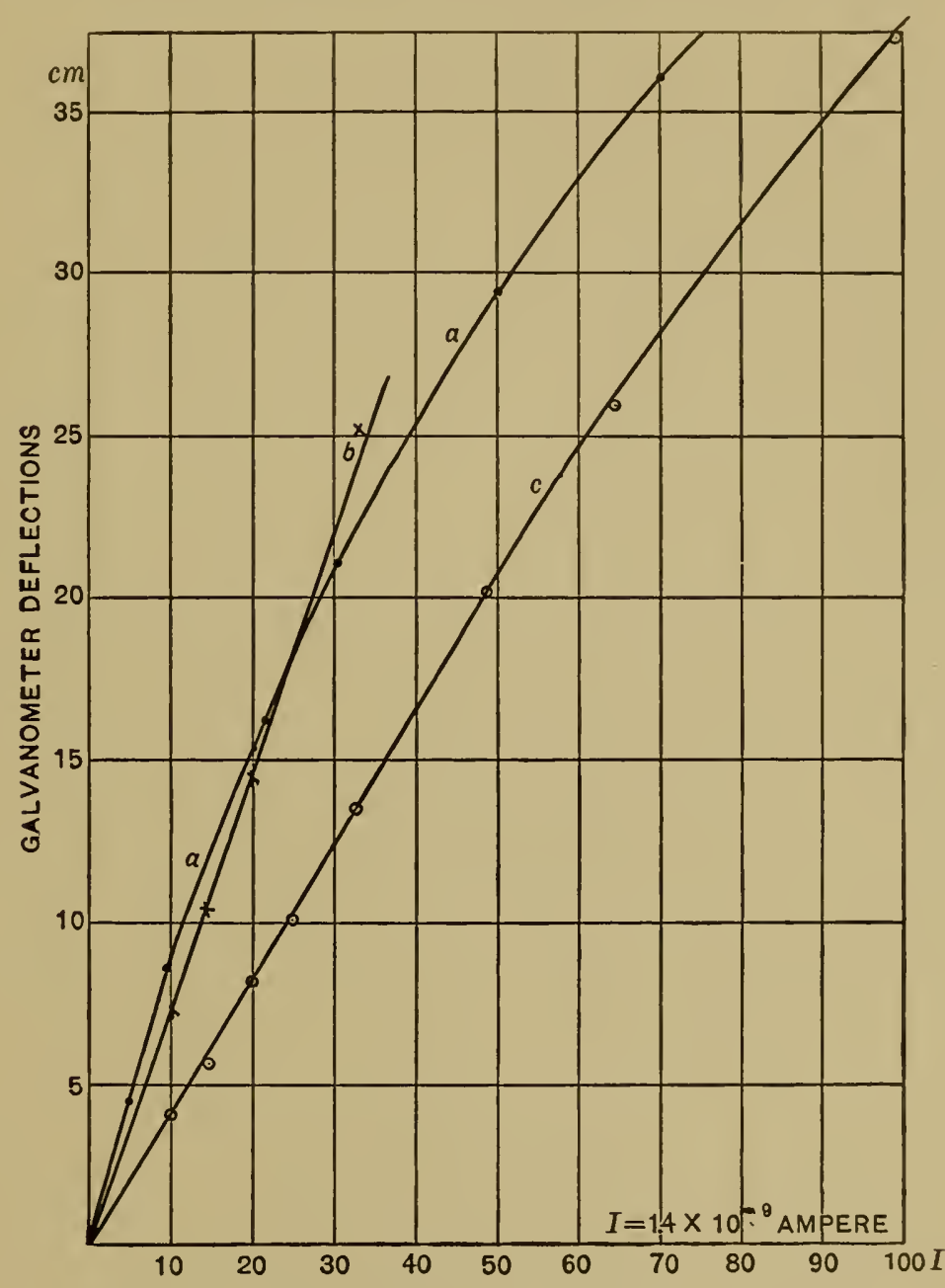

Fig. 7.-Proportionality of Galvanometer Deflections.

proportional to the current up to about $8 \mathrm{~cm}$. Using a Io magnet system (magnets $\mathrm{I} .4 \mathrm{~mm}$ long), curve $b$, the proportionality of deflections with current holds for values as large as 16 to $20 \mathrm{~cm}$, depending upon the sensitiveness, which in this case was about $2 \times \mathrm{IO}^{-10}$ ampere. The proportionality is of course greater for the less sensitive instrument. 
The deflections observed when using the 6-ohm coils (four coils in parallel) were proportional to the current up to $30 \mathrm{~cm}$. This is the only instrument tried in which the period was affected by varying external resistance, which indicates that in the other galvanometers the damping is due to the air.

Curve $c$ gives the deflections for the $20 \mathrm{ohm}, 32 \mathrm{~mm}$ diameter coils (in parallel), with a system of 12 magnets ( 6 at each end) I. 6 to I. $8 \mathrm{~mm}$ long. Here the proportionality holds for deflections as large as $30 \mathrm{~cm}$. The magnet system weighed about $8 \mathrm{mg}$ which reduced the sensitiveness to $3.5 \times \mathrm{IO}^{-10}$ ampere for a full period of 12 seconds.

Of all these galvanometers, in which about a dozen different styles of magnet systems were used, the one having the smallest coils (I $8 \mathrm{~mm}$ diameter) proved the most satisfactory except for proportionality. As has just been shown, by a judicious selection of longer galvanometer magnets, the proportionality of deflections with current may be made to hold true for large deflections with but slight loss in sensitiveness for a given period.

( $f$ ) Magnetic shiclding.- In places where the magnetic field is subjected to great variations it is necessary to surround the galvanometer with an iron shield, which is most efficient when it is in the form of spherical or cylindrical shells of different thicknesses ${ }^{40 a}$ of iron. For convenience in working, it is desirable to have the system of shields occupy a small space, which necessitates the use of metal shells of small diameter. This is a desirable feature for efficiency in shielding, but, since the shells usually become permanent magnets in handling, there is great difficulty in lengthening the period of the galvanometer needle. It is therefore a matter of trial in placing the control magnets in such a position that they weaken the combined fields of the shields. In fact, it was found easier to place a short magnet (steel file) so that it controlled the suspended system and then weaken its field than to overcome the complex field of the shields, by means of the control magnets.

\footnotetext{
40a Wills, Phys. Rev. 24, p. 243, 1907, finds that for both spherical and cylindrical systems the best conditions are obtained when the radii of the shells are in geometrical progression.
} 
For magnetically shielding the small coil galvanometer used in this work four sections of annealed soft steel pipe, about $30 \mathrm{~cm}$ long, diameter $7,10,15$, and $20 \mathrm{~cm}$, respectively, and + to $6 \mathrm{~mm}$ thick, were provided. In practice only the two middle tubes were used, the inner one being discarded on account of the unusual difficulty experienced in controlling the galvanometer, as just explained.

The mirror was viewed through slits $\mathrm{I} \mathrm{cm}$ high cut into the shields. Although this is supposed to produce an asymmetrical field it made no appreciable difference, since the slits were far below the coils. An inner shield was made from Swedish iron (Fig. 6), which had a circular hole, bored vertically to admit the suspended system and the coils, which were mounted in paraffin. This inner magnetic shield was found to be superior to the others just described, since it is easier to anneal and does not become a permanent magnet in handling. The shield with the glass windows, $w, w$, serves as a further protection against air currents. By taking the leads out through the bottom of the galvanometer, they will not interfere with the outer shields. In the present work the Swedish iron proved as efficient as the system of soft-steel pipes and no outer shields were provided.

It is customary to provide a symmetrical pair of control magnets ( 30 to $40 \mathrm{~cm}$ above the coils) placed upon a contrivance which permits an independent horizontal rotation and a vertical motion. ${ }^{41}$ This is desirable in work extending over a long time, for the astaticism of the needle system is constantly changing, which requires a frequent adjustment of the control magnets in order to keep a fairly constant galvanometer period.

3. The Construction of Sensitive Bolometers.-In the bolometer the sensitiveness is closely proportional to the square root of the surface, so that in spectrum energy work, where the bolometer strip is narrow, the sensitiveness attainable through the bolometer is limited.

The general complaint against the bolometer is its drift, which is of two kinds, viz, (I) a slow shift of the zero scale reading due to an unequal change in resistance in the bolometer strips and 
(2) a fluctuation of the readings due to air currents and magnetic perturbations. This ought to be the most pronounced for bolometers having large surfaces, although some writers are of the opinion that the narrow strip bolometer is subject to the greatest variations from mechanical vibrations and air currents. There are so many possible sources of trouble in a bolometric outfit that it may be worth while to notice them. (I) The auxiliary galvanometer is subject to magnetic perturbations, and, if exposed to great temperature changes, its sensitiveness is changed, due to a variation in the resistance of the coils. The sensitiveness and zero reading is also constantly changing, due to variations in the magnetic field. (2) The bolometer strip is affected by air drafts and, if very thin, by mechanical vibrations. (3) The electric circuits are subject to temperature (resistance) changes which vary the bolometer current. (4) The storage-battery current is irregular, due to changes in temperature and to polarization. The gases surrounding the bolometer may affect the reading. Lummer and Pringsheim ${ }^{42}$ found that variations in the amount of moisture in the air changed the sensitiveness of the bolometer.

If, therefore, one is working in a well-lighted (southern exposure) and well-ventilated room, a drift is to be expected. As an illustration of this, Abbot (loc. cit.) found "that the difference of radiating power between an observer's black coat, distant $2 \mathrm{~m}$ from the balanced bolometer, and the walls of the room which his coat momentarily hid, threw the spot of light off the scale some $40 \mathrm{~cm}$, while the observer's naked hand within a meter of the bolometer turned the galvanometer needle round and round." The writer found that his balanced bolometer (not in use for observations, however) would not shift I $\mathrm{mm}$ in half a day when it was cloudy, but on bright days, with every passing cloud, or on windy days the scale readings would fluctuate back and forth through several centimeters. It is therefore advisable to work in a basement room located on the north side of a building. In this connection it may be noticed that the radiometer is more self-contained, and all its parts are concentrated in a small space in which it is easier to control the temperature. The same is true of the thermopile.

\footnotetext{
${ }^{42}$ Lummer and Pringsheim, Ann. der Phys. (3) 63, p. 398, i 897.
} 
(a) Best Resistance of Bolometer and Balancing Coils.-In all the bolometers that have been used by foreign investigators the four arms were chosen of equal resistance. Lummer and Kurlbaum ${ }^{43}$ consider the bolometer a simple Wheatstone bridge which is at its maximum sensitiveness when the four arms and the galvanometer are of equal resistance, and the e. $\mathrm{m}$. $\mathrm{f}$. is constant. In reality we vary the e. $\mathrm{m}$. f.; and Reid ${ }^{4 t}$ has shown that consequently the resistance of the balancing coils should be considerably larger than that of the bolometer. Child and Stewart ${ }^{45}$ have shown experimentally that the sensitiveness is increased by having the resistance of the balancing coils several times that of the bolometer strips. Abbot ${ }^{46}$ has also shown that the maximum sensibility is very nearly attained when the balancing coils are upward of four times the resistance of the bolometer strips, and the galvanometer resistance is not less than 0.6 or more than four times the resistance of the bolometer strip. This has led to the general adoption (in America) of a resistance for the compensation coils which is from ro to 20 times that of the bolometer strips.

The equation ${ }^{47}$ showing the relation between bolometer sensitiveness $S$, the bolometer current $I$, the temperature coefficient, $e$, of the part of the strip exposed, $a$, the resistance of the bolometer strips, $r$, the absorption coefficient of the surface exposed to radiation, $A$, the emissivity of the whole surface, $E$, the area of the surface, $F$, the heat capacity, $W$, and the galvanometer constant, $k$, is:

$$
S=\frac{I}{8} e a k \sqrt{r} \frac{f_{1}(A) f_{3}(F)}{f_{2}(E) f_{1}(W)}
$$

From this it will be noticed that the sensitiveness is increased by decreasing the heat capacity and the emissivity; and by increasing the bolometer current, the temperature coefficient, the resistance, the absorption coefficient, and the surface. Since for a given thickness and width of strip the resistance is proportional to the surface, it follows from the above equation that the sensitiveness is proportional to the square root of the exposed surface.

${ }^{43}$ Lummer and Kurlbaum, Wied. Ann., 46, p. 204; 1892.

${ }^{44}$ Reid, Amer. Jour. Sci., 35, p. 160; 1888.

${ }^{45}$ Child and Stewart, Phys. Rev., 4, 1). 502 ; 1897.

${ }^{46}$ Annals of the Astrophys. Obs., Vol. I. 
'The resistance of a wide bolometer may be increased by placing several strips side by side. For $n$ such strips in series the resistance will be increased $n$ times, and for the same current the sensitiveness will be increased by $\sqrt{n}$. If the breadth of one strip is increased $n$ times, the current can be increased $n$ times; but since the resistance of the strip is reduced $n$ times, the sensitiveness remains as before. It follows, therefore, that the greatest sensitiveness is attainable in a bolometer having a large surface. This is well illustrated in the work of Lummer and Kurlbaum ${ }^{47}$ who were thus able to use a galvanometer having a sensitiveness of only $i=\mathrm{I} .5 \times 1 \mathrm{IO}^{-9}$ ampere. For the same reasons the sensitiveness of a linear bolometer
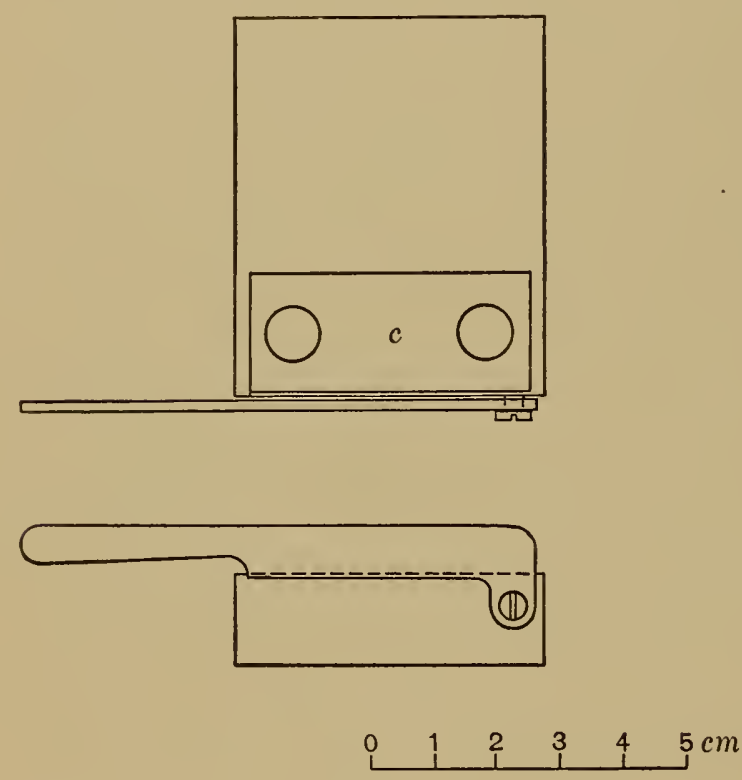

Fig. 8. is very limited, and recourse must be had to a sensitive galvanometer.

4. Design of a Bolometer.Langley's bolometer ${ }^{48}$ is the only one described in which the complete instrument is enclosed in a metal case to shield it from temperature changes and drift. The instrument was intended for use in a vacuum, and hence it was complicated in construction. He used a bridge with a sliding metal contact to balance the bolometer arms. In the instrument used by the writer the friction contact gave so much trouble that a mercury contact was devised. The ideas contained in the present design were incorporated after an examination of all the important bolometers previously described, and hence are not new. The instrument as a whole, however, contains simplifications which it is hoped may be of use to others. It is possible to place the bolometer in a vacuum, but since the sensitiveness attained 
is not commensurate with the difficulties arising in the use of the instrument, no attempt has been made to do so. This form of bolometer is of course less portable than the one in which the balancing coils are in a separate box, but the cases are rare where it is not possible to keep the bolometer stationary and rotate the prism table or the other spectrometer arm.

As above stated, the mechanical difficulties involved in making a thin bolometer strip are such that platinum is the best adapted. Platinum in silver wire may be hammered or rolled into flat strips. In an accurately adjusted jewelers' roll it is possible to press bare platinum wire $0.025 \mathrm{~mm}$ thick into strips $0.003 \mathrm{~mm}$ thick. To do this the rolls are screwed together quite tight (not as tight as possible as one would suppose) and the wire is passed back and forth many times, in the meantime applying heavy lubricating oil,

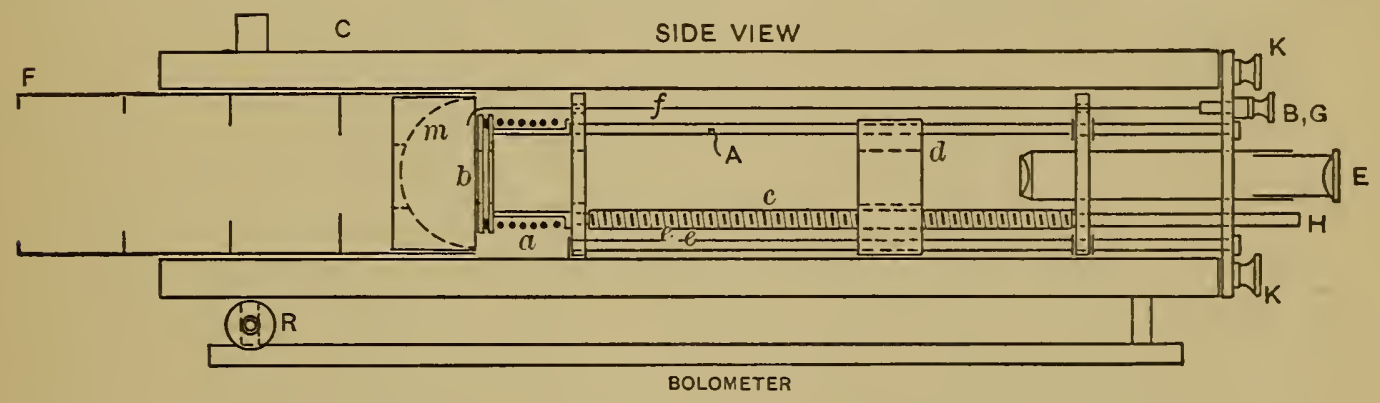

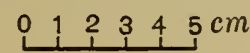

Fig. 9.

which seems to aid in producing a thin strip. During the operation the wire must be annealed frequently. Platinum in silver foil of any desired thickness can now be purchased (Sy and Wagner, Berlin), from which strips of any desired width can be cut. The strips can be cut accurately to the desired dimensions on a dividing engine, but there is danger of tearing the foil unless a suitable cutting tool is made. The steel shears shown in Fig. 8 were constructed for the purpose of cutting strips of the same width with a smooth edge, and have proved very serviceable. A pair of bolometer strips is cut at one stroke from a double sheet of the platinum in silver foil. In this figure, $c$, is a clamp with screws to secure the foil while cutting. The rest of the apparatus is self-explanatory. The difference in the width of a pair of strips was found to be of the order of o.or $\mathrm{mm}$. 
'To construct a bolometer in which the resistances of the strips are equal within I per cent, to have the surfaces as nearly equal as possible, and, after this adjustment, to cover these strips electrolytically with platinum black and then with soot is a difficult operation. In cases where an absolute measure of

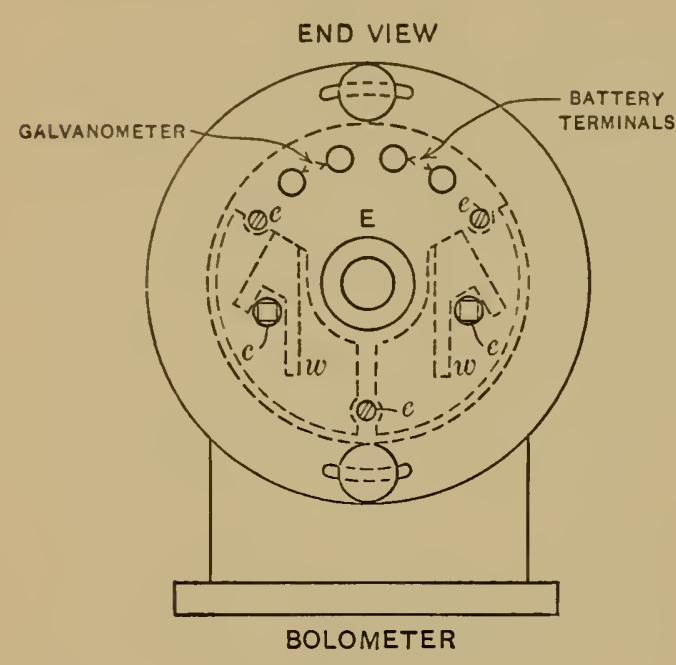

Fig. 10. radiation is not desired, it is unnecessary to use the electrolytic bath, candle smoke being sufficient, in which case there is but little difficulty in blackening the bolometer. Linear bolometers which are less than o.oor mm thick are torn by the surface tension of the electrolytic bath, or the nitric-acid bath used in removing the silver from the platinum, and are extremely difficult to adjust. Paschen overcame this difficulty in part by stroking the platinum in silver strip (mounted on an ebonite holder) with a drop of nitric acid, held in the end of a small glass tube, until the silver was dissolved and the two arms were of equal resistance. In the present work the silver was removed from the strips before mounting them.

In blackening the bolometer strips it was found that the resistance would sometimes change. The platinum strips were, theręfore, annealed, before mounting, by heating them electrically, to a red heat, which served the additional purpose

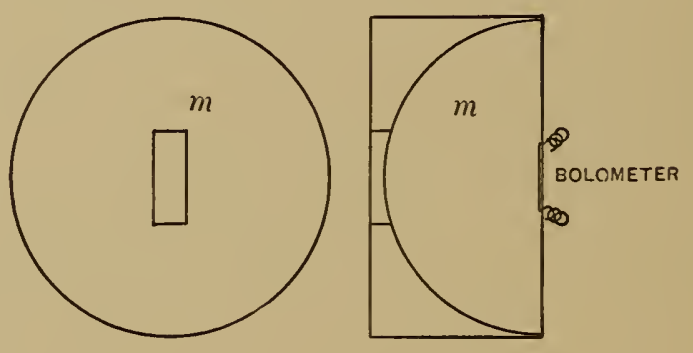

\begin{tabular}{l}
$0 \quad 1 \quad 2 \quad 3$ \\
\hdashline$\quad 1 \quad 3$
\end{tabular}

Fig. 11.-Hemispherical mirror. of burning off a black residue which remains after dissolving the silver from the platinum and which is liable to make a poor contact. In mounting the bolometer strips on the holder, the one to be exposed to radiation is first soldered in place. The unexposed strip is made a little longer, so that it will have a slightly 
greater resistance, which by subsequent resoldering is made equal to that of the exposed strip.

The present bolometer consists of three separate parts, viz, the funnel, $F$, for admitting the energy to the bolometer, Fig. 9, the outer double-walled case, $C$, which may be filled with water (running water has a variable temperature), and the frame, $A$, holding the bolometer strips, the compensation coils, and the balancing wires with sliding mercury contact, $d$, Figs. I 2 and I4. The frame $A$, Figs. 9 and $\mathrm{r} 2$, can be easily removed from the case, which is an important factor. The concave hemispherical mirror $m$, Fig. I I, is used to reflect back to the bolometer strip, $b$, Fig. I 3 , any energy which has not been absorbed by it. The support and adjusting screws for this mirror is attached to the bolometer frame $A$, but is not shown in these illustrations.

In Fig. Io is shown an end view of the bolometer, in which it will be noticed that the bolometer strip is adjustable about a vertical axis by means of the screws, $k, k$. The horizontal adjustment, $R$, is not shown in detail. The two pairs of binding posts, $G$ and $B$, connect the galvanometer and battery to the bolometer by means of heavy 
twisted copper wire. The frame itself for supporting the screws, $c, c$, Figs. 9 and $\mathrm{I} 2$, is composed of three rods, $e, e, e$, attached to two brass plates, $h, h$. The small telescope, $E$, is used to adjust the bolometer in the spectrum.

In Fig. I 2 is given a more detailed drawing of the frame, $A$, The threads of the screws, $c, c$, for adjusting the slide wires. have a pitch of $\mathrm{I} \mathrm{mm}$. In this figure are shown the bobbin, $a$, for carrying the two balancing arms of the bridge, the manganin wire being wound noninductively. The metal disk, $b$, for supporting the bolometer strips is attached to the bobbin, $a$, by insulating material, $i$, and is covered with a

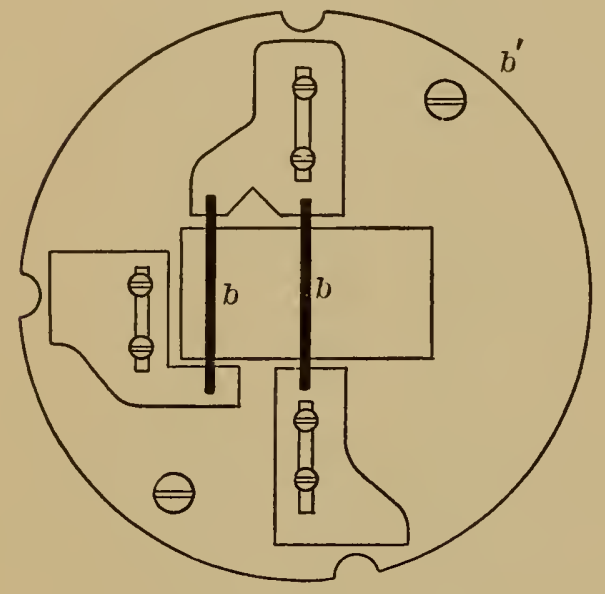

Fig. 13.-Support for bolometer strips. thick $(0.3 \mathrm{~mm})$ piece of mica, as indicated at $o$, Fig. I 2.

The details of the bolometer strips, $b, b$, and their support are shown in Fig. I3. The bolometer strips are of platinum $0.00 \mathrm{I}$ to $0.003 \mathrm{~mm}$ thick, 0.2 to $0.5 \mathrm{~mm}$ wide, to $\mathrm{mm}$ long, and have a resistance of 0.7 to $3 \mathrm{ohms}$; and are soldered to adjustable copper terminals. Other platinum foil in silver, purchased abroad, had a thickness of 0.0005 to $0.003 \mathrm{~mm}$ (of $\mathrm{Pt}$ ). The heavy copper wires, f, Fig. 9, are soldered directly to these terminals, using rosin.

In Fig. I4 are shown the two hollow fiber sliding contacts. The holes for the wires are shown at $w, w$. It will be noticed that these sliding contacts are made hollow by drilling into them, in two directions, from the top. In this manner, a mercury holder is produced that is open only at the top. ${ }^{48 a}$ Since the mercury column surrounding the wire, $w, w$, is Io to I $2 \mathrm{~mm}$ long and at least $\mathrm{x} .5 \mathrm{~mm}$ thick around the slide wire, there is no difficulty whatever with bad contacts.

In previous designs at least three different methods were employed in connecting the bolometer, galvanometer, slide wire

48a The writer is indebted to Mr. Harring, of the instrument division, for his ingenuity in fulfilling this condition. 
and storage battery (see Figs. 15 and 16 ). 'The following is a modification of the method used by Julius (loc. cit.). He moved the conducting wire leading from the bolometer to the battery. In the present case the wires are stationary and the mercury contact piece, $d$, Fig. I 2, mounted on a screw, $c$, is moved. In Fig. I 6 is shown the method of wiring the bolometer. The heavy copper lead wires are not shown in the figures, except $f$, Fig. 9. The bolometer strips, $b, b$, in Fig. 16 are also to be noticed in Fig. I3, while the balancing coils $a$, $a$ (2O ohms each) of manganin are wound noninductively on the bobbin, $a$, Fig. I2. The sliding contacts, $d, d$, are also shown in Fig. I2, where the wires are indicated at $w, w$. The latter pass through insulated bushings in the frame, $h, h$. For testing the sensitiveness two fine insulated wires are soldered to the ends of the exposed bolometer strip, Fig. I6. By connecting these wires with a high resistance, say I00,000 ohms, the deflection obtained by thus unbalancing the bridge is a measure of the sensitiveness of the galvanometer. For prolonged routine observations, a
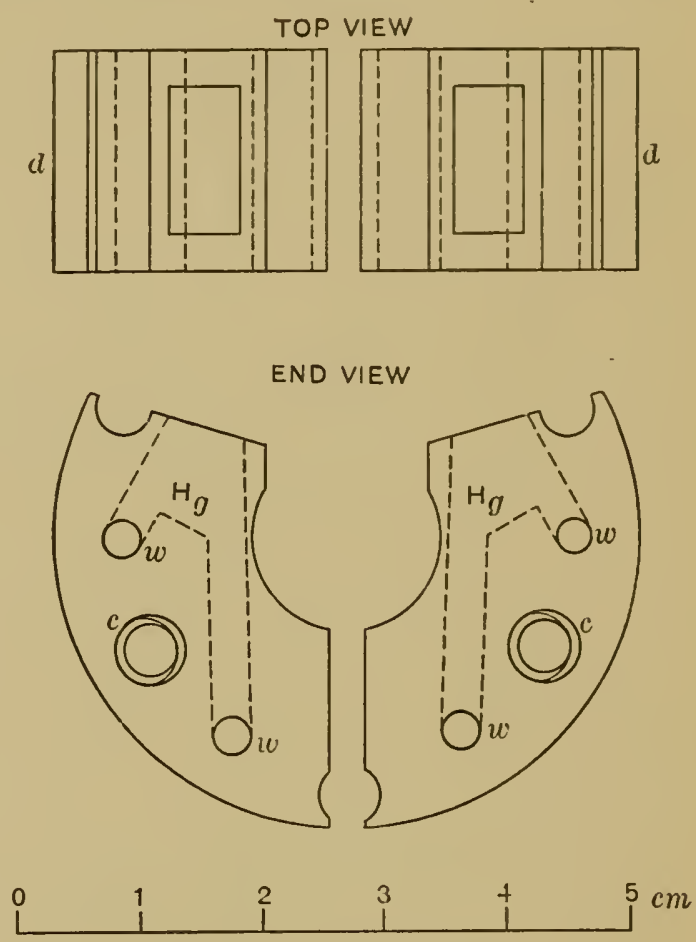

Fig. 14.-Sliding contact. shunt box for reducing the sensitiveness of the galvanometer by $\frac{1}{5}, \frac{1}{10}, \frac{1}{25}, \frac{1}{50}$, and $\frac{1}{100}$, a reversing switch and a switch to shunt the bolometer, as just indicated, may be mounted in one box, which greatly facilitates the work. The largest wires, $f^{\prime \prime}, f^{\prime \prime}$, Fig. I6, of constantan are $1.4 \mathrm{~mm}$ diameter and have a resistance of 0.3 ohms per meter. By moving the mercury contact o.o I $\mathrm{mm}$ the change in resistance is $0.000 \mathrm{O} 3 \mathrm{ohm}$, or by joining the wire as shown by the dotted lines, Fig. I6, the change in resistance is $0.000015 \mathrm{ohm}$. For the coarse adjustment, constantan wires $f^{\prime}$, $f^{\prime}$, having a diameter of $0.63 \mathrm{~mm}$ and a resistance of $\mathrm{r} .4 \mathrm{ohms}$ 
per meter were used. With this combination it was possible to balance the bolometer so close (using the coarse adjustment) that on permanently closing the galvanometer circuit the deflection would be only from 2 to $3 \mathrm{~cm}$, which was then brought back to zero by means of the fine adjustment. By connecting the sliding contact and balancing coils, as indicated, it is possible to balance the bridge with but little adjustment on the slide wire, $f^{\prime}, f^{\prime}$. An increase in resistance on one side of the bridge corresponds to a decrease on the other side. This permits the use of less wire, and the whole can be confined in a smaller space than would have been possible in some of the previous instruments if an attempt had been made to place the bolometer and balancing coils and slide wire in one case.
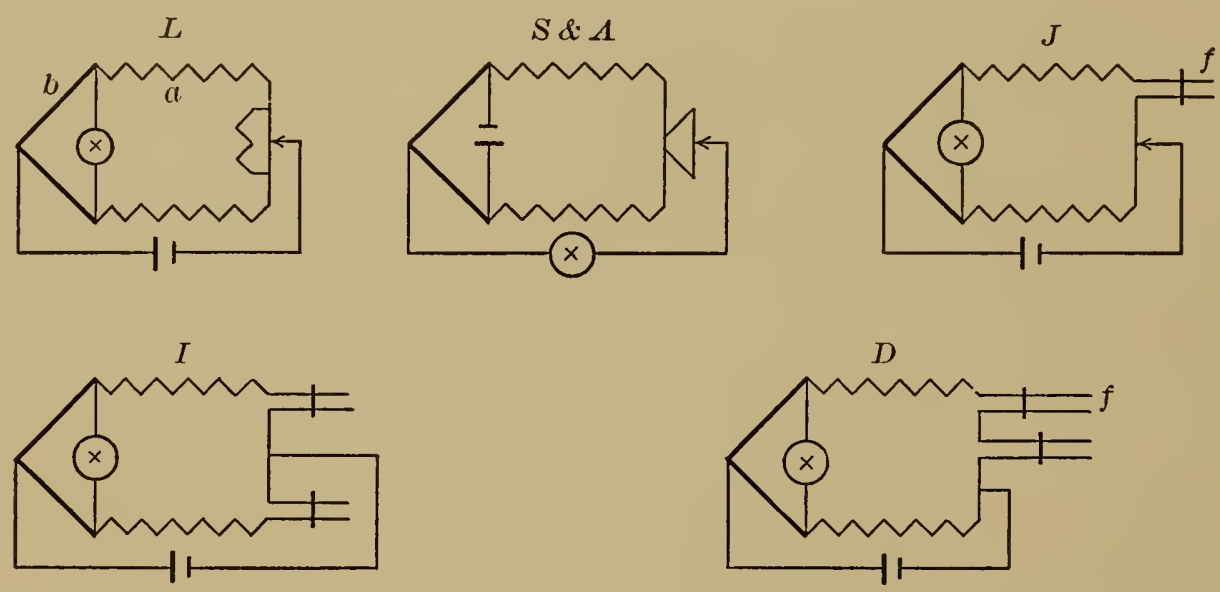

$L=$ LANGLEY, SNOW, ASCHKINASS, JULIUS, INGERSOLL, DONATH.

Fig. 15.-Various bolometer arrangements.

The sliding contact, Fig. I4, containing the mercury is made of fiber, which is elastic and makes a close contact, so that no mercury works out in sliding it along the wire, $w, w$. The openings at the top are closed with cork and there is no danger of spilling mercury. It is important to use flexible wire (twisted cord) between the bolometer and the galvanometer to reduce thermal effects. In the original design it was intended to use manganin for the balancing coils and slide wires, because of its low temperature coefficient and low thermoelectric power against copper. It was found that the manganin amalgamated so seriously with the mercury and became so brittle that constantan 
was used for the slide wires in spite of its high thermoelectric power, which, however, is of minor importance, since the wires are situated in the interior of the case away from the bolometer arms, where there are air currents.

The use of copper for a slide wire (as one writer has suggested) is objectionable on account of its high temperature coefficient. If the ends of the bolometer arms, where they are soldered to the balancing coils, are kept at the same temperature by shielding them from radiation, there will be no thermoelectric currents developed, and if they are equally warmed the currents developed at the ends will be in opposite directions and will neutralize each other. The result of the Peltier effect and the Thomson effect has never been considered in radiation instruments except in the radiomicrometer where Boys (loc. cit.) calls attention to the fact

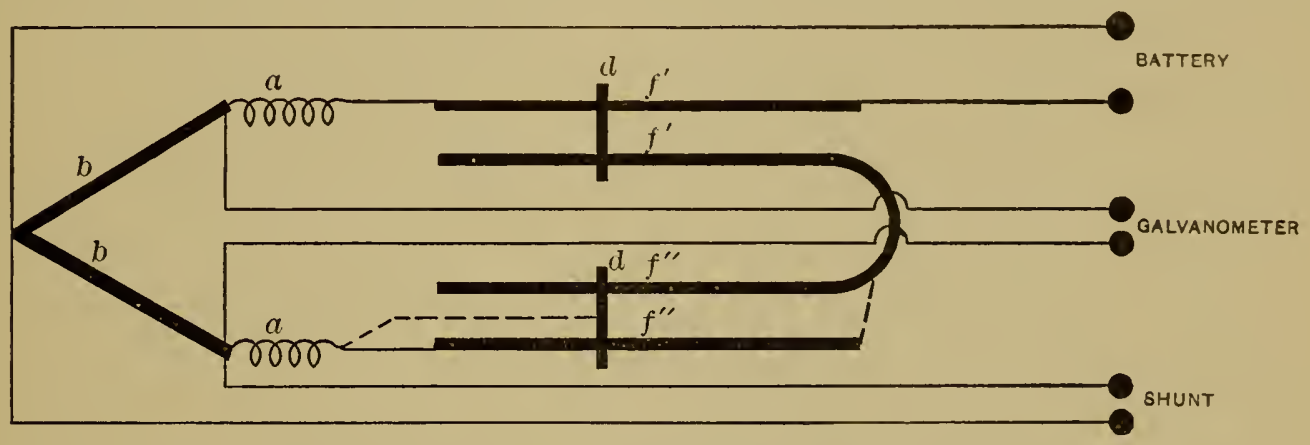

Fig. 16.-Arrangement of present bolometer circuit.

that the exposed junction will not become so warm as it otherwise would on account of heat conduction and Peltier action, which tends to send a current in the opposite direction to that producing it. In a platinum bolometer these two effects as well as the thermoelectric power are small ${ }^{49}$ and, since they are opposed to each other must have little effect on the quantities measured. In iron and nickel the Peltier effect is much larger, and when used in a thermopile (Rubens) it is important that the junctions have as small heat capacity as possible.

5. Comparison of Sensitiveness of Various Bolometer-Galvanometer Combinations. - Important data on sensitive radiation meters, and particularly that relating to bolometers, are given in Table IV. It will be noticed that the thermopile is as sensi-

${ }^{49}$ See Gray, Magnetism and Electricity, and Landolt and Börnstein Tables. 
tive as the bolometer. By using iron-constantan wire 0.06 to $0.08 \mathrm{~mm}$ thick the high thermal capacity is reduced. The resistance will be somewhat higher, but that is not objectionable, since the galvanometer resistance may also be made higher. The sensitiveness of the radiometer is obtained by comparing it with the bolometer. Although the radiometer is less efficient than the bolometer, it probably absorbs as much of the incident energy. Since the radiometer deflections were larger per unit area than the bolometer-galvanometer deflections, it is safe to assume that the radiometer was just as sensitive as, if not more so, than the bolometer. The long period is of course a serious objection in certain classes of work. In Table IV it will be noticed that the high temperature sensitiveness of the various instruments has been attained by the use of a highly sensitive long-period galvanometer, by using a large bolometer current, and by placing the scale at a great distance from the galvanometer. Assuming that the sensitiveness is proportional to the square of the period for a scale at $\mathrm{I} \mathrm{m}$, and a bolometer current of 0.04 ampere, it will be seen from column io, Table IV, that the temperature sensitiveness of the various instruments falls in two groups. To the first group belong the earlier instruments of Rubens, of Snow, and of Paschen, with a sensitiveness of about $5^{\circ} \times \mathrm{IO}^{-5}$ per mm deflection. To the second group belongs a more sensitive combination of Paschen's, and the writer's instrument, in which I mm deflection corresponds to a rise in temperature of $\mathrm{II}^{\circ} \times \mathrm{IO}^{-6}$ and $9^{\circ} \times \mathrm{IO}^{-6}$, respectively. In other words, the instruments of the latter group have the same sensitiveness, and any increase is to be attained by lengthening the scale distance; the bolometer current of 0.04 ampere is about the maximum limit for accuracy. The sensitiveness of the writer's instruments could have been further increased by lengthening the scale distance to $2.5 \mathrm{~m}$, when the temperature sensitiveness would have been $3^{\circ}: 6 \times \mathrm{IO}^{-6}$, and by doubling the galvanometer period, when the sensitiveness would have been $9^{0} \times \mathrm{IO}^{-7}$ against Paschen's $\mathrm{I}^{\circ} \times \mathrm{IO}^{-6}$. Such a computation is of course illusory, on account of damping in the galvanometer. On actual trial (but not for the magnet system quoted) for a full period of 30 seconds the sensitiveness of the galvanometer was $i=7 \times$ IO $^{-11}$ ampere. 
6. Comparison of Bolometer with Thermopile.-The efficiency of the bolometer and the thermopile is reduced by losses due to reflection and radiation from the receiving surface and to heat conduction to the unexposed parts. The loss of energy in the thermopile due to the Peltier effect has been considered in discussing that instrument. The loss of energy due to reflection is about 4 per cent (Kurlbaum ${ }^{50}$ ). Assuming the bolometer to be made of platinum $0.5 \times 0.002 \mathrm{~mm}$ cross section, and the thermopile of 20 junctions of iron and constantan wire $0.06 \mathrm{~mm}$ diameter, it can be readily shown that the cross section of the thermopile is about 56 times that of the bolometer, and from their heat conductivities, for the same temperature gradient, that the loss of heat by conduction in the thermopile is about roo times that of the bolometer. But the temperature gradient at the ends of a bolometer strip carrying an electric current may be $50^{\circ}$ to $100^{\circ}$, so that the heat lost by conduction may be about the same for both instruments. Since the temperature of the bolometer is from 50 to $100^{\circ}$ higher than the thermopile, the loss of heat per second due to radiation in the former is from 2 to 3 times that of the latter. But the mass of the thermopile is 5 times, while its specific heat is 3.3 times, that of the bolometer. Hence, to raise the temperature of thermopile and the bolometer to the same extent, $16(5 \times 3.3)$ times as many heat units must be applied to the former. Since the loss by radiation is 3 times as great from the bolometer, it will require about 5 times as long for the thermopile to reach a steady temperature. In practice, however, on account of the blackening of the surface, which modifies its emissivity, the bolometer is not so quick in its action as here computed.

From these considerations, as well as from the mechanical difficulties in constructing a thermopile of wire less than $0.05 \mathrm{~mm}$ in diameter and keeping the resistance low, it appears that the thermopile can not be made so quick in its action as the bolometer, and hence is not so well adapted where a quick automatic registration of the galvanometer deflections is desired. But, as will be shown presently, since it is difficult to read large deflections

${ }^{50}$ Kurlbaum: Ann. der Phys. (3) 67, p. 846; 1899 . Ann. der Phys. (4) 2, p. 555; 1900. 
accurately in less than a 4 to 5 seconds swing of the galvanometer system, a thermopile of 0.06 to $0.08 \mathrm{~mm}$ wire, which attains a steady temperature in this interval of time, is not objectionable, and, since it is less disturbed by air currents (being at room temperature), it may be the more reliable instrument (see Table $V$ ). Neither instrument, however, compares with the radiometer in steadiness. The amount of work done on emission, absorption, and reflection spectra, as well as the accuracy attained, in the infrared to $\mathrm{I} 5 \mu$, where the radiometer deflections were again and again only a few tenths of a millimeter, would not have been possible with these instruments. In a recent examination of reflection spectra of minerals, using a thermopile, the accuracy attainable without repeating the readings several times was far from that of the radiometer, although the actual deflections were larger.

The present experimental comparison of the thermopile, of $0.08 \mathrm{~mm}$ iron and constantan wire, and the platinum bolometer was undertaken in order to determine the accuracy attainable in measuring a constant source of radiant energy, and hence to learn the feasibility of substituting the thermopile for the troublesome bolometer. Within experimental error it has been established by Langley, by Rubens, and by Julius that the bolometer (galvanometer) deflections are proportional to the current flowing through the bolometer and also to the amount of energy falling upon the bolometer strip. It remained, therefore, to determine whether the present bolometer behaved likewise and also whether the same accuracy is attainable with the thermopile.

To this end a bolometer was constructed with the greatest care. It was annealed before adjusting the resistance of the strips, covered electrolytically with platinum black after the method of Kurlbaum ${ }^{57}$ and then smoked over gauze wire over a paraffin candle. The resistances of the bolometer strips were 1.782 and I.797 $(\Delta=$ o.or 5) ohms, respectively. After blackening them they were 1.766 and $1.818\left(\Delta=0.05^{2}\right)$ ohms, respectively. The width of the bright strips was $0.50 \mathrm{~mm}$, which was increased to 0.56 $\mathrm{mm}$ after blacking. The length was II $\mathrm{mm}$ and thickness less than $0.002 \mathrm{~mm}$. The bolometer current was 0.04 ampere and throughout the following experiments there was no difficulty due to air currents. Magnetic disturbances were at a minimum and 
conditions for accurate measurements were as perfect as one could expect.

TABLE V.

Comparison of Bolometer and Thermopile.

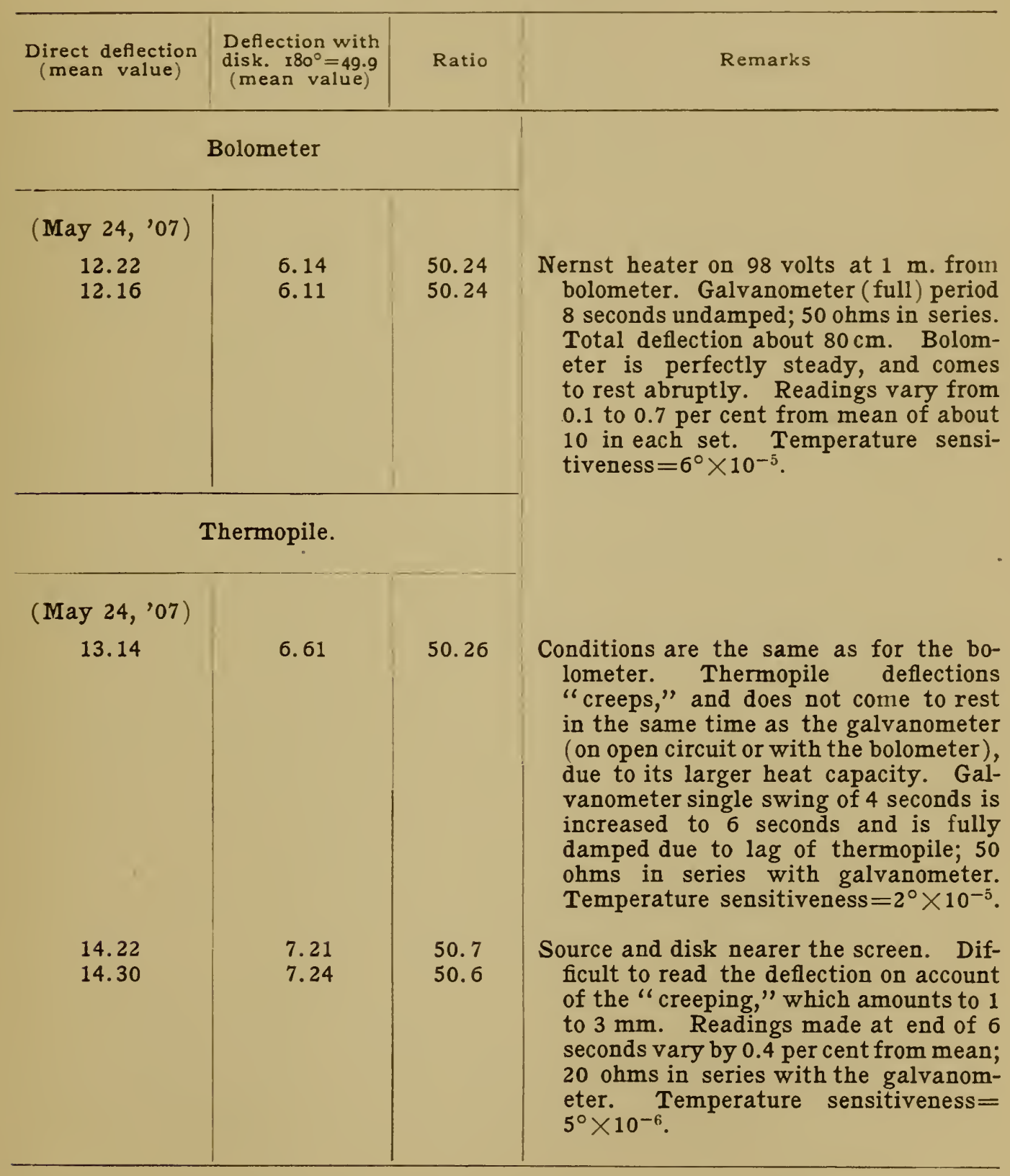

The thermopile of 0.08 wire (20 junctions covered with a slit $0.5 \mathrm{~mm}$ wide), already described, showed a slight lag in registering the energy received. Although this was not marked, there was a 
tendency for the deflection to creep instead of stopping abruptly, as in the case of the bolometer. This was most marked in large deflections and necessitated exposing the thermopile to radiation for a clefinite time ( 6 seconds) and taking the zero at the expiration of an equal interval of time. The results are given in Table $\mathrm{V}$. The last two values for the thermopile are vitiated by radiation from the rotating disk, to be explained later. The results show that there is no great difference in the two instruments. It was necessary, however, to note the time of exposure of the thermopile, which is not convenient for large deflections. The estimation of the relative merits of the bolometer and the thermopile is, therefore, a personal one, and from the experience gained it may be said that for measuring intense sources the bolometer is the more accurate (when working to 0.5 per cent) unless great precautions be taken in making the thermopile readings.

The theoretical temperature sensitiveness of the thermopile was considerably greater than that of the bolometer, as was found on subsequent computation. It may be added, therefore, that if the bolometer sensitiveness had been increased by increasing the current through it, there would have been greater unsteadiness in the galvanometer readings.

7. Bolometric Usage.- The use of the null method in bolometric measurements has been suggested, i. e., to actually measure the change in resistance rather than to read the direct deflections. Wadsworth ${ }^{51}$ has shown, however, that the deflection method is quicker and better than the zero method, since it involves no disturbance of the contacts in any part of the bridge. At the highest sensitiveness the zero method is practically excluded for accurate measurements of very feeble radiations.

For the sake of completeness, the method of determining the temperature sensitiveness of the bolometer strip is included here. The method ${ }^{52}$ consists in unbalancing the bridge by placing a high resistance, e. g., I00,000 ohms, in parallel with one of the bolometer strips and noting the resulting deflection. Then, knowing the resistance and the temperature coefficient of the bolometer

${ }^{51}$ Wadsworth, Astrophys. Jour., 5, p. 268; 1897.

52 Rubens and Ritter, Wied. Ann., 40, p. 62; r 890. 
strip, one can compute the change in temperature, $\Delta t$, corresponding to I $\mathrm{mm}$ deflection from the equation:

$$
\Delta t=\begin{array}{cc}
r & \mathrm{I} \\
s & \delta d
\end{array}
$$

where $r=$ the resistance of the bolometer strip, $s=$ shunt resistance ( $\mathrm{rOO}, \mathrm{OOO}$ ohms), $\delta=$ the temperature coefficient (about $0.003+$ for platinum), and $d=$ the galvanometer deflections in $\mathrm{mm}$. Snow ${ }^{53}$ placed a large resistance permanently in parallel with the bolometer strip and unbalanced the latter by closing a shunt around a part of the former. This method was also employed to determine the sensitiveness from day to day. Its use is open to one objection, viz, the change in current in the bolometer strip introduced by placing a high resistance in parallel is sufficient to disturb the temperature equilibrium in the bolometer case, and it is necessary to wait a few seconds for the galvanometer to become steady. However, since this test is not very frequent, it is more convenient than the radiation test. Lummer and Pringsheim ${ }^{54}$ compared the daily variation in sensitiveness by exposing the bolometer strip to the radiation from a "black-body" heated with boiling water. The latter has the disadvantage that the amount of atmospheric water vapor as well as the barometric pressure varies from day to day, and hence the amount of energy received by the bolometer is not perfectly constant. Angstrom, ${ }^{55}$ and Kurlbaum ${ }^{56}$ have given methods for determining the sensitiveness in absolute value.

The change in absorption and emission of platinum black and of soot with thickness was investigated by Kurlbaum. ${ }^{57}$ He found that a deposit of soot weighing $25 \mathrm{mg}$ per $\mathrm{dm}^{2}$ emits 94 per cent as much energy (at $100^{\circ}$ C.) as does a complete radiator, while

\footnotetext{
${ }^{53}$ Snow, Phys. Rev., 1, p. $32 ;$ i 893.

${ }^{54}$ Lummer and Pringsheim, Wied. Ann., 63, p. 399; 1897.

${ }_{55}$ Angstrom, Acta. Reg. Soc. Upsala, June, I 893.

${ }^{56}$ Kurlbaum, IVied. Ann., 51, p. 59 I, I894; 61, p. 420, 1897; (6.5, p. 746, 1898.

${ }^{57}$ Kurlbaum, Wied. Ann. (3), 67, p. 846, 1899.

The electrolyte used in depositing platinum black consisted of 1 part of platinum chloride, 30 parts of water, and 0.008 of lead acetate. He used a current density of 0.03 ampere per $\mathrm{cm}^{2}$, and 4 volts for 3 minutes. The lead acetate causes the platinum black to adhere. The writer has found that for narrow bolometer strips the platinum black deposits more rapidly on the edges than on the flat surface.
} 
a deposit of $s_{3} \mathrm{mg}$ per $\mathrm{dm}^{2}$ of platinum black is required to have the same emissivity. From this it was assumed the bolometer absorbs a similar amount. Paschen ${ }^{58}$ however, appears to be the only one who attempted to make his bolometer a more complete absorber of radiation by placing it in the focus of a highly-polished concave hemispherical mirror, as shown in Fig. I I. He used this arrangement in finding the maxima of his energy curves and found that the constant, 2920, in the Wien displacement law was increased about 4 per cent by using the mirror. Another method of "blackening" the bolometer is to have the strip in the form of a hollow blackened cylinder with a slit to admit the energy to be measured. In this form the resistance of the strip is low, and hence there is difficulty in attaining sufficient sensitiveness.

The adaptability of a radiation meter for a particular kind of work seems never to have been considered. The bolometer is well adapted for measuring intense sources, using a short period galvanometer, but it has not been a great success in measuring weak sources of radiation. A very sensitive radiometer behaves more like a photographic plate (which is cumulative in its action, however) and useful in registering feeble sources. The thermopile is the most useful in measuring weak radiation, such as the selective reflection of long heat waves (Rubens, loc. cit.) where a radiometer can not be used on account of the opacity of its window. It is interesting to note that the radiometer has been used successfully in measuring heat from stars (Nichols, loc. cit., Table III). It is perhaps the most efficient instrument which can be used for such work. This is due to the fact that the star image is small. A radiometer with a small vane, the size of the star image, will have a short period, and since its sensitiveness may be made as high as for a large vane, it is well adapted for such work. On the other hand, the number of thermo-junctions that can be covered with a star image must be very limited, hence, gain in sensitiveness must be attained by increasing the period of the galvanometer. For the same reason the bolometer, on account of its large surface, can not be used as efficiently as the radiometer for this particular problem. That is to say, the great sensitiveness 
required would have to be attained through the galvanometer by lengthening its period, thus subjecting it to magnetic perturbations. For spectrum energy work, using a fine linear surface, the bolometer has been used to great advantage, especially in the investigation of the dispersion of fluorite and rock salt.

(a) Errors Resulting from Lack of Balance of Bolometer.-The errors introduced into the observed galvanometer deflections as a result of not keeping the bolometer balanced appears never to have been considered. It has been frequently noticed in this paper that the bolometer is subject to a continuous drift, due to a slow unbalancing of the bridge arms. In the present test the bolometer was

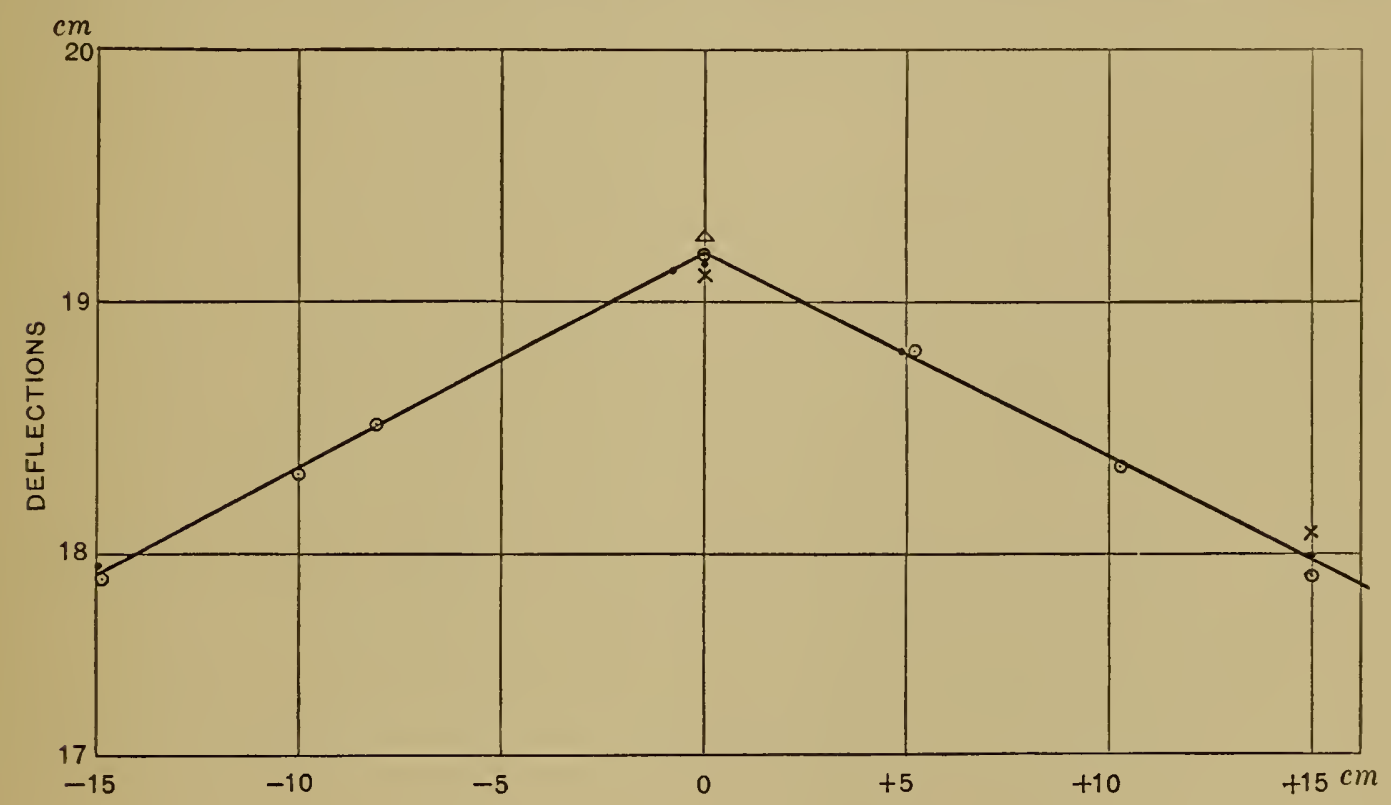

Fig. 17.-Variation insensibility with balancing of bolometer.

unbalanced by moving the mercury contact on the compensating wires. The source of energy was a i io-volt Nernst-lamp heater on a 98-volt storage battery circuit, which supplied a constant current.

In Fig. I 7 is shown the change in the galvanometer deflections (ordinates) when the bolometer is exposed to the radiation from the Nernst-heater, after unbalancing the bolometer bridge. The amount of unbalancing is given in galvanometer deflections (abscissæ), positive or negative, depending upon the direction of the unbalancing. In Fig. I 7 the zero deflection indicates that the galvanometer deflection was the same on open and on closed 
bolometer circuit, i. e., that the bolometer was perfectly balanced. The positive and negative deflections indicate the change in the zero of the galvanometer reading on closing the bolometer circuit after the latter was unbalanced, corresponding to a drift. The different series of observations are indicated by dots, circles, crosses, etc. The lack of symmetry in the two branches of the graph may be due to the galvanometer not being level. The galvanometer sensitiveness was about $3 \times 10^{-10}$ ampere, and the bolometer current was 0.04 ampere.

The results show that a lack of balance of $2 \mathrm{~cm}$ introduced an error of I per cent in the resulting galvanometer deflections. From this it will be seen that it is necessary to keep the bolometer balanced to less than $\mathrm{I} \mathrm{cm}$ in order to insure accuracy in the final results.

\section{SELECTIVE RADIATION METERS.}

The well-known fact that the resistance of selenium changes, when exposed to light, has been applied to photometric measurements. If an alloy could be produced which has its maximum sensitiveness (i. e., its resistance change greatest) for those wave lengths to which the eye is most sensitive, it would be possible to devise a method for measuring radiant efficiencies which is far superior to present methods of comparing the total radiation to the luminous radiation. In the ultraviolet the photo-electric effect has been applied to measure the radiation from the mercury arc. $^{59}$

Little is known in regard to this class of radiation meters. Since they are highly selective their application is limited, but if the proper combination could be found having a sensibility curve similar to the eye it would have a wide application in photometric work. If the transformation of radiant energy into electrical energy is as complete in the photo-electric effect as in a bolometer it would be a steadier instrument, since the former is not subject to such perturbations as is the bolometer.

${ }^{59}$ Küch and Retschinsky, Ann. der Phys. (4) 20, p. 563; 1906. 
VIII. CHANGE IN SENSITIVENESS OF INSTRUMENTS.

Various observers have tested the bolometer and have found that as a meter of radiant energy it indicates a direct proportionality (in galvanometer deflections), with a change in intensity of the incident energy. Hence, it is unnecessary to reduce its indications by a known amount in order to obtain an accurate measure of the energy falling upon the bolometer strip. Large deflections of the auxiliary galvanometer, however, are not proportional to the current, and hence a shunt or series resistance must be introduced in the galvanometer circuit to reduce the deflections to the region within which proportionality holds, or the necessary corrections must be applied from the calibration curve of the galvanometer. The sensitiveness may also be reduced by changing the current in the bolometer circuit.

On the other hand it has been shown that, on account of the Peltier effect, which may introduce errors of about I part in 300 to 400 , it is advisable to keep the equivalent deflections less than $30 \mathrm{~cm}$ (scale at $\mathrm{I} \mathrm{m}$ ) when using an iron-constantan thermopile. Since the galvanometer deflections must also be kept small, the best procedure is to put a large resistance in series with the thermopile. The use of a sectored disk would appear better, for then all the errors are transferred back to the disk. However, the following experiment shows that the motion of the disk may introduce slight errors, which must be determined and eliminated in quantitative work.

(a) Experiment with a Sectored Disk.-In comparing the relative merits of the bolometer and the thermopile, the simplest method appeared to be to reduce the intensity of the source by a known amount, by using a sectored disk the angular openings of which are accurately known. It will be noticed that while the ratios of energy transmitted by the sectored disk were in close agreement in any series of measurements (see Tables $V$ and VI), the numerical values were in all cases higher than the true ones. In other words, the disk transmitted too much energy or the apparent opening was larger than the true one. It remained therefore to be shown whether this is due to diffraction (of the very long wavelengths) or to lack of proportionality in the registering of the energy by the bolometer and by the thermopile. The method I5298-08-8 
TABLE VI.

Reliability of Bolometer Measurements.

\begin{tabular}{c|c|c}
\hline Direct deflection & $\begin{array}{c}\text { Deflection with } \\
\text { disk }\end{array}$ & Ratio \\
(mean of 6 to ro readings) & \\
\hline \multicolumn{2}{|c}{ Disk opening $240^{\circ}=66 . S 27$} \\
\hline (May 27, '07) & & \\
$9.42 \mathrm{~cm}$ & $6.33 \mathrm{~cm}$ & 67.23 \\
9.35 & 6.28 & 67.25 \\
11.82 & 7.95 & 67.25 \\
9.11 & 6.12 & 67.2 \\
& & \\
8.94 & 6.04 & 67.5 \\
13.31 & 8.99 & 67.6 \\
& &
\end{tabular}

Jisk opening $120^{\circ}=33.406$

\begin{tabular}{c|c|c}
\hline (May 28, '07) & & \\
15.82 & 5.65 & 35.70 \\
11.56 & 4.14 & 35.75 \\
& & \\
May 27, '07) & & \\
12.31 & 4.28 & 34.8 \\
& & \\
30.40 & 10.53 & 34.7 \\
& & \\
13.75 & 4.70 & 34.5 \\
& & \\
(May 25, '07) & & 33.56 \\
14.15 & 4.75 & \\
17.04 & 5.68 & \\
\hline
\end{tabular}

Diski opening $180^{\circ}=50.125$

\begin{tabular}{c|l|l}
\hline May 24, '07) & & \\
$17.17 \mathrm{~cm}$ & $8.65 \mathrm{~cm}$ & 50.37 \\
17.21 & 8.64 & 50.20 \\
& & \\
& & \\
\hline
\end{tabular}

Galvanometer period 8 seconds, and vibration is undamped; $20 \mathrm{ohms}$ in series with the galvanometer. Temperature sensitiveness $=6^{\circ} \times 10^{-5}$ C. High values are due to radiation from moving disk, which is $0.5 \mathrm{~m}$ from screen.

Galvanometer period 14 seconds and vibration is just damped. Temperature sensitiveness $=1^{\circ} .2 \times 10^{-5} \mathrm{C}$.

Galvanometer period 14 seconds.

Galvanometer period 8 seconds. Disk better shielded than in previous experiments and is closer to screen-6 $\mathrm{cm}$ from it. Heater $150 \mathrm{~cm}$ from bolometer; screen at $80 \mathrm{~cm}$.

14 ohms in galvanometer circuit. Galvanometer period 14 seconds. Nernst heater on 74 volts.

No resistance in galvanometer circuit; results show that high value is not due to lack of proportionality of galvanometer deflections.

Nernst heater on 95 volts. $20 \mathrm{ohms}$ in galvanometer circuit. Total deflection is about $45 \mathrm{~cm}$.

Nernst heater on 98 volts at $1 \mathrm{~m}$ from bolometer. Galvanometer period 8 seconds. $30 \mathrm{ohms}$ in series with galvanometer. Total deflection about 80 $\mathrm{cm}$. The individual deflections vary from 0.2 to 0.5 per cent from mean. 
of observation consisted in taking from 5 to ro readings without the disk, then a similar number with the rotating disk interposed, followed by a number without the disk.

The first test was to determine whether the rotating disk $(30 \mathrm{~cm}$ diameter, I.3 meters from the bolometer) affected the instrument, and it was found that the resulting deflections, I to $2 \mathrm{~mm}$, were no larger than those due to stray radiation reflected from the stationary disk. A heavy black cardboard shield was then placed between the bolometer and the disk ( $0.5 \mathrm{~m}$ from the disk) and similar screens were placed around the source, which was 2 meters from the bolometer. No radiation was detected from the stationary disk, whether the open or closed part of the disk faced the bolometer; but unfortunately this test was not made for the moving disk. The disk with the $240^{\circ}$ opening gave values 0.5 per cent too high (see Table VI, observations of May 27). The results with the $120^{\circ}$ disk ( 6 openings of $20^{\circ}$ each) were in still greater error. The space between the bolometer and the shield was then entirely enclosed, and with the disk close to the opening $(7 \times 10 \mathrm{~cm})$ in the shield the discrepancy became still greater. It was then found that the increased transmission is due to the moving disk and depended upon the distance of the disk from the screen.

It was further shown that the transmission was proportional to the speed, so that the $240^{\circ}$ disk (true transmission 66.827 per cent ${ }^{60}$ ) gave values from 69.3 to 77.2 per cent. In Fig. I 8 are plotted the galvanometer deflections (abscissæ) for different distances of the disk from the screen. The latter was $80 \mathrm{~cm}$ from the bolometer, and had an opening in it which was the size of the openings in the sectored disk. No radiation was observed from the stationary disk, nor from the shields back of it when the open sector was before the bolometer. The speed of the disk was such as is used in photometry, and was kept constant for each series of observations. In the lower curve for the $240^{\circ}$ disk the speed was slow and there was a flicker on viewing it. The curves show that the maximum radiation occurs when the disk is about $6 \mathrm{~cm}$ from the shield, and it disappears immediately on stopping the disk.

60 These disks and their constants were supplied by Dr. Hyde. This Bulletin, $\underline{\mathbf{2}}$ p. I, 1906. 
The disk was run continuously for a complete series of measurements, and no deflections greater than i to $2 \mathrm{~mm}$ were observed from it immediately after stopping the rotation. In these tests the motor was shielded from the bislometer. On removing the shield and the disk and on running the motor the deflections were from I to $3 \mathrm{~mm}$. The experiment shows that the sectored disk is not as applicable as one would suppose, unless one determines the corrections which in two series of experiments were found to be in very close agreement. In the present curves the galvanometer was at its full sensitiveness (no resistance in series), so

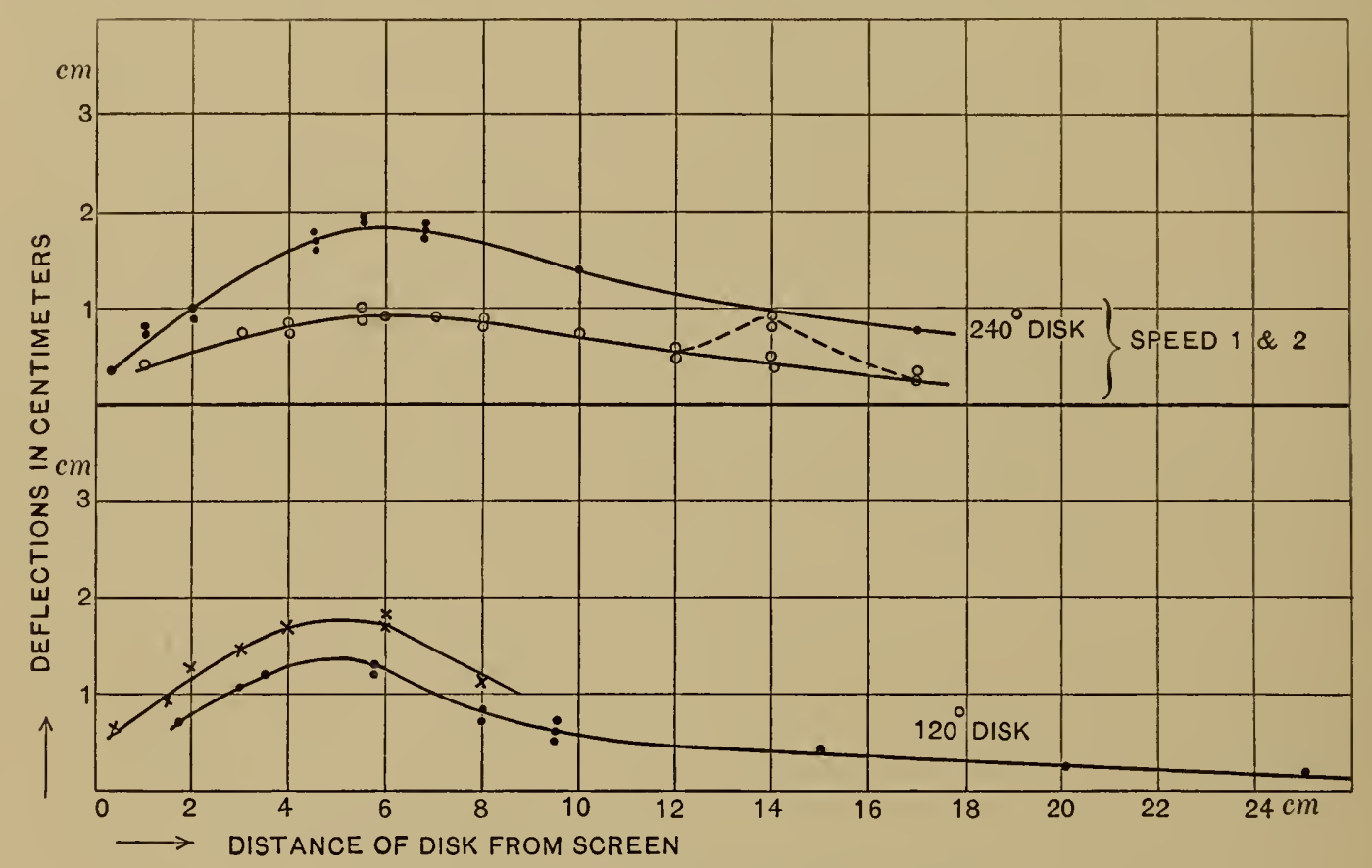

Fig. 18.-Radiation from moving sectored disk.

that in the actual experiments (Table VI) the error was less. For the $240^{\circ}$ disk where the error in the deflections was only I or $2 \mathrm{~mm}$ the correction reduces the observed values close to the true one.

In connection with a bolometer or a thermopile it is possible to run the disk at a very much slower speed than used here; this will reduce the errors in question to a minimum.

From the consistency of the ratios in each series, which is of the order of 0.2 to 0.3 per cent, it will be noticed that the bolometer is a very reliable instrument in spite of its mechanical weakness. 


\section{SUMMARY.}

The present paper deals with four instruments for measuring radiant energy, viz, the radiomicrometer, the linear thermopile, the radiometer, and the bolometer with its auxiliary galvanometer.

As a result of this historical inquiry and by experiment it was shown that the radiomicrometer is capable of great improvement, by reducing its weight, by lengthening its period, and by placing it in a vacuum. It was further shown, that on account of para- and dia-magnetism the sensitiveness of the radiomicrometer is very limited, perhaps only a fifth of the best bolometers described.

It was also shown that the Rubens thermopile is as sensitive as the best bolometer, and that its heat capacity can be greatly reduced by using thinner (0.06 to $0.08 \mathrm{~mm}$ diameter) wires, which are made shorter, thus keeping the resistance low. The computed errors, due to the Peltier effect, are about I part in 300 . The thermopile is not so well adapted as is the bolometer for instantaneous registration of radiant energy and it does not admit so great a range in variation of sensibility, but on account of its greater steadiness it commends itself for measuring very weak sources of radiation, e. g., the extreme ultra-violet and infra-red region of the spectrum.

By a direct comparison it was shown that the radiometer can be made just as sensitive as the bolometer, but its period will be much longer. It was found that the radiometer is not selective in its action, and hence that it can be used for measuring ultraviolet radiation. The main objection to the use of a radiometer is its long period, but since it is easily shielded from temperature changes, and since it is not subject to magnetic perturbations, this long period is of minor importance so long as we are dealing with a constant source of radiation. In spectrum energy work its usefulness is limited to the region in which the window is transparent, to $20 \mu$. The fact that the radiometer deflections can not be obtained in absolute measure is a minor objection, since in but few cases (thus far at least) has it been necessary to thus obtain the deflections. The action of a radiometer is somewhat analogous to a photographic plate, in that it will detect weak radiation, provided one can wait for it, and, on account of its great 
steadiness, is of all the instruments considered, probably the best adapted to search for infra-red fluorescence.

A bolometer installation is so distributed that it is difficult to shield from temperature changes. In spite of its small heat capacity, the bolometer has a "drift" due to a slow and unequal warming of the strips. Air currents which result from the hot bolometer strips also cause a variation in the deflections of the auxiliary galvanometer. Nevertheless, despite these defects, it is the quickest acting of the four instruments considered and is the best adapted for registering the energy radiated from a rapidly changing source. For precision work it is necessary to keep the bolometer balanced to less than I cm deflection.

The auxiliary galvanometer is the main source of weakness in measuring radiant energy, and in places subject to great magnetic perturbations a period greater than 5 seconds, single swing, is to be avoided. Hence, although a greater sensitiveness is possible, the working sensibility of the various galvanometers studied is of the order of $i=2 \times \mathrm{IO}^{-10}$ ampere per mm deflection on a scale at I $\mathrm{m}$. Under these conditions the various bolometers used were (as a fair estimate of the recorded data) sensitive to a temperature difference of $4 \times 1 \mathrm{IO}^{-5}$ degree to $5 \times 1 \mathrm{IO}^{-6}$ degree per $\mathrm{mm}$ deflection, on a scale of I meter. The galvanometer sensibility was found to be closely proportional to the period.

A direct comparison was also made of the relative accuracy of the thermopile and the bolometer in measuring intense and weak sources of radiation, and the results show that there is little preference, other than a personal one, in these two instruments.

The manner of reducing the sensitiveness of these instruments is of importance in precision work. The use of a rotating sectored disk for reducing the intensity of the source is liable to introduce errors, which must be taken into account.

It may be added that these tests were made in a building which is isolated from mechanical and magnetic disturbances, and hence under the most favorable conditions.

WASHINGTON, October I, 1907. 